\title{
The duration of sleep promoting efficacy by dual orexin receptor antagonists is dependent upon receptor occupancy threshold
}

\author{
Anthony L Gotter ${ }^{1}$, Christopher J Winrow ${ }^{1}$, Joseph Brunner ${ }^{1}$, Susan L Garson' ${ }^{1}$, Steven V Fox ${ }^{2}$, Jacquelyn Binns ${ }^{2}$, \\ Charles M Harrell', Donghui Cui ${ }^{3}$, Ka Lai Yee ${ }^{3}$, Mark Stiteler², Joanne Stevens², Alan Savitz², \\ Pamela L Tannenbaum², Spencer J Tye ${ }^{2}$, Terrence McDonald', Leon Yao², Scott D Kuduk ${ }^{4}$, Jason Uslaner ${ }^{2}$, \\ Paul J Coleman ${ }^{4}$ and John J Renger ${ }^{1^{*}}$
}

\begin{abstract}
Background: Drugs targeting insomnia ideally promote sleep throughout the night, maintain normal sleep architecture, and are devoid of residual effects associated with morning sedation. These features of an ideal compound are not only dependent upon pharmacokinetics, receptor binding kinetics, potency and pharmacodynamic activity, but also upon a compound's mechanism of action.
\end{abstract}

Results: Dual orexin receptor antagonists (DORAs) block the arousal-promoting activity of orexin peptides and, as demonstrated in the current work, exhibit an efficacy signal window dependent upon oscillating levels of endogenous orexin neuropeptide. Sleep efficacy of structurally diverse DORAs in rat and dog was achieved at plasma exposures corresponding to orexin 2 receptor $\left(\mathrm{OX}_{2} \mathrm{R}\right)$ occupancies in the range of 65 to $80 \%$. In rats, the time course of $\mathrm{OX}_{2} \mathrm{R}$ occupancy was dependent upon receptor binding kinetics and was tightly correlated with the timing of active wake reduction. In rhesus monkeys, direct comparison of DORA-22 with GABA-A modulators at similar sleep-inducing doses revealed that diazepam produced next-day residual sleep and both diazepam and eszopiclone induced next-day cognitive deficits. In stark contrast, DORA-22 did not produce residual effects. Furthermore, DORA-22 evoked only minimal changes in quantitative electroencephalogram (qEEG) activity during the normal resting phase in contrast to GABA-A modulators which induced substantial qEEG changes.

Conclusion: The higher levels of receptor occupancy necessary for DORA efficacy require a plasma concentration profile sufficient to maintain sleep for the duration of the resting period. DORAs, with a half-life exceeding $8 \mathrm{~h}$ in humans, are expected to fulfill this requirement as exposures drop to sub-threshold receptor occupancy levels prior to the wake period, potentially avoiding next-day residual effects at therapeutic doses.

Keywords: Dual orexin receptor antagonist, Suvorexant, Receptor occupancy, Residual effects

\section{Background}

As a primary arousal signal in wake control, orexin signaling is necessary for normal circadian regulation of consolidated wakefulness; exogenous application of orexin neuropeptides or optogenetic activation of orexin neurons induce arousal and genetic loss of orexin signaling is associated with narcoleptic symptoms [1,2]. Endogenous

\footnotetext{
*Correspondence: john_renger@merck.com

${ }^{1}$ Department of Neuroscience, Merck Research Laboratories, West Point, PA, USA

Full list of author information is available at the end of the article
}

orexin peptide levels oscillate over the course of the day: secretion during waking hours induces a peak in orexin levels late in the active phase, and rapidly decreasing activity precedes a nadir in levels during the inactive phase $[3,4]$. Orexin-A (OX-A) and -B (OX-B) are processed peptide products of the HCRT (hypocretin) gene, which encodes the prepro-orexin peptide [5]. OX-A has similar affinity for both orexin-1 and -2 receptors $\left(\mathrm{OX}_{1} \mathrm{R}\right.$ and $\mathrm{OX}_{2} \mathrm{R}$, respectively), while OX-B selectively favors $\mathrm{OX}_{2} \mathrm{R}$ binding [6]. Exogenous administration of OX-A is most effective in promoting wakefulness when applied during

\section{Biomed Central}


inactive-phase periods when the endogenous levels are normally low [7-9]. Conversely, blocking orexin activity with dual orexin receptor antagonists (DORAs) is most easily measured during the active phase [10-12].

Therapy targeting insomnia requires defined pharmacodynamic timing. Unlike most other central nervous system therapeutics, compounds utilized in the therapeutic treatment of insomnia will, ideally, promote sleep throughout the resting period, maintain normal sleep architecture, and avoid residual effects upon waking, thus allowing for full wakefulness during the subsequent active period. This time-limited efficacy requires pharmacokinetic exposure and sufficient central receptor occupancy levels to drive sleep efficacy when desired, and reduced compound exposure to avoid residual effects upon waking. This limitation of duration of activity makes the half-life $\left(\mathrm{T}_{1 / 2}\right)$ of $\gamma$-aminobutyric acid (GABA-A) receptor modulators a key defining feature of their clinical utility. Next-day/carry-over effects, in particular, are well-documented undesirable mechanismrelated adverse effects of conventional therapies with long half-lives $[13,14]$. The current standards of care, benzodiazepine and non-benzodiazepine GABA-A receptor modulators, can also be associated with bothersome morning sedation and cognitive residual effects. In contrast, the current data on DORAs suggest that these compounds induce physiological sleep and demonstrate only mild residual effects despite relatively long plasma $\mathrm{T}_{1 / 2}[10,12,15-18]$. Preclinical studies of compounds with balanced potency at $\mathrm{OX}_{1} \mathrm{R}$ and $\mathrm{OX}_{2} \mathrm{R}$, such as DORA22 , an analog of MK-6096 [2,18,19], demonstrate little or no effect on electroencephalogram (EEG) spectral frequency distribution, suggesting that blockade of orexinmediated wakefulness allows sleep to occur that is similar to that measured in vehicle-treated controls [20].

Pharmacologically, the duration of sleep-promoting efficacy depends not only upon a compound's mechanism of action, but also upon its pharmacokinetics, receptorbinding kinetics and potency, as these properties dictate the timing of receptor occupancy required for in vivo effects important for a compound's overall activity and clinical utility. Clearly, rapid central nervous system penetration is essential for sleep-onset efficacy, and a moderate pharmacokinetic $\mathrm{T}_{1 / 2}$ and sufficiently high receptor occupancies are required for sleep maintenance throughout the desired resting period. However, to avoid next-day residual effects, compound levels must drop below exposures required for minimum effective receptor occupancy by the onset of wakefulness to avoid residual sleep effects. In principle, compounds that are effective at a low receptor occupancies are challenged to restrict sleep promoting effects to the resting phase, compared to mechanisms that require a higher occupancy threshold that are less likely to exhibit carry-over effects for a given pharmacokinetic profile and $\mathrm{T}_{1 / 2}$. Here, we characterize the pharmacokinetic and receptor occupancy properties underlying the timing of efficacy elicited by structurally distinct DORAs including DORA- 12 and DORA-22, close analogs of suvorexant and MK-6096 whose chemical properties have been described previously $[19,21,22]$. The ensemble of pharmacokinetic, receptorbinding kinetics and pharmacodynamic properties of DORAs appear advantageous to restricting the wakeinhibition efficacy of these compounds to the resting phase.

\section{Results}

\section{OX-A levels are associated with wakefulness} across species

To more precisely define the timing of changes in orexin levels, their relationship with arousal and therefore the available signal window for the DORAs over the course of the circadian day, OX-A levels in cerebrospinal fluid (CSF) were determined by meso-scale immunoassay and correlated with baseline active wake as measured by polysomnography (PSG) in nocturnal and diurnal preclinical species. In nocturnal mice and rats, OX-A levels progressively drop during the inactive period, reaching a nadir in the second half of this period, and accumulate over the course of the dark (active) period (Figure 1A). Mean time in active wake generally mimics these OX-A levels. In diurnal dogs and rhesus monkeys, OX-A levels build during the light (active) period and fall during the resting period, coincident with increased arousal during the day and decreased wakefulness at night (Figure 1B). These observations predict that DORAs will have maximum efficacy in the late dark phase of nocturnal species and the late light phase of diurnal animals which correlates to the active periods of both types of species.

\section{DORA efficacy in rats is most salient during the active phase}

The sleep-promoting effects of DORAs were greatest during the active phase when orexin levels were highest in normal rats entrained to a 12:12 light:dark cycle. When administered during the mid-active phase, DORA$22(30 \mathrm{mg} / \mathrm{kg})$, an MK-6096 analog structurally distinct from suvorexant and DORA-12, promoted sleep characteristic of a DORA: active wake was attenuated for up to $8 \mathrm{~h}$, and both delta and REM sleep were increased for up to $6 \mathrm{~h}$ following treatment (Figure 2A). The magnitude of wake-reducing activity was diminished when normal rats were administered DORA-12 just prior to the inactive phase onset and was accompanied by small variable increases in delta and rapid eye movement (REM) sleep (Figure 2B). Importantly, changes induced by DORA-22 administered just prior to the inactive phase trend in the same direction as that seen in vehicle-treated animals progressing from the active 


\section{A Nocturnal Species}
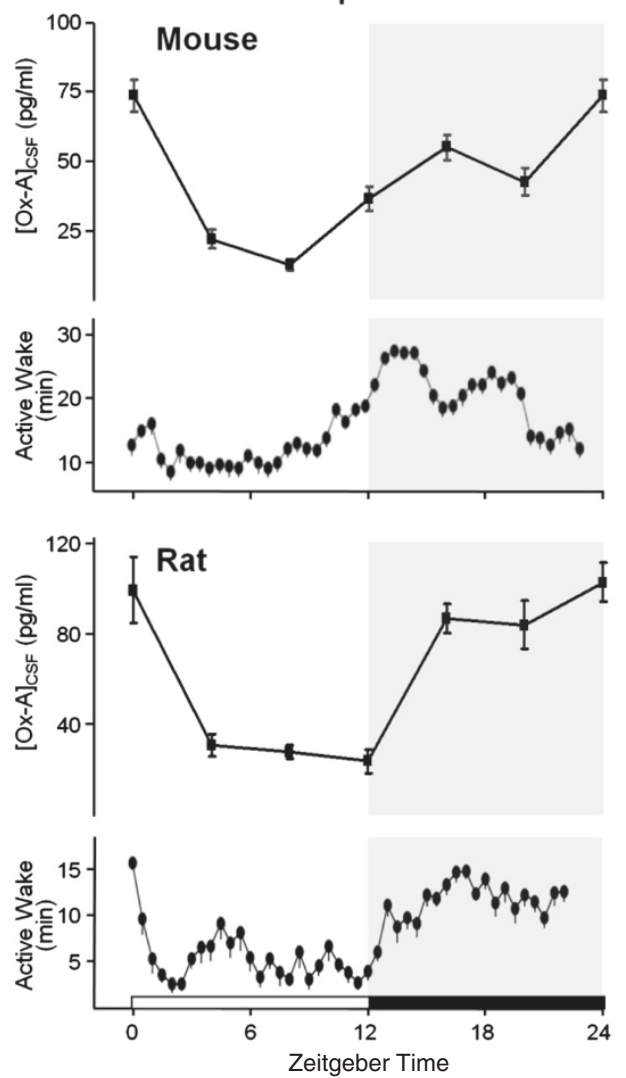

B Diurnal Species
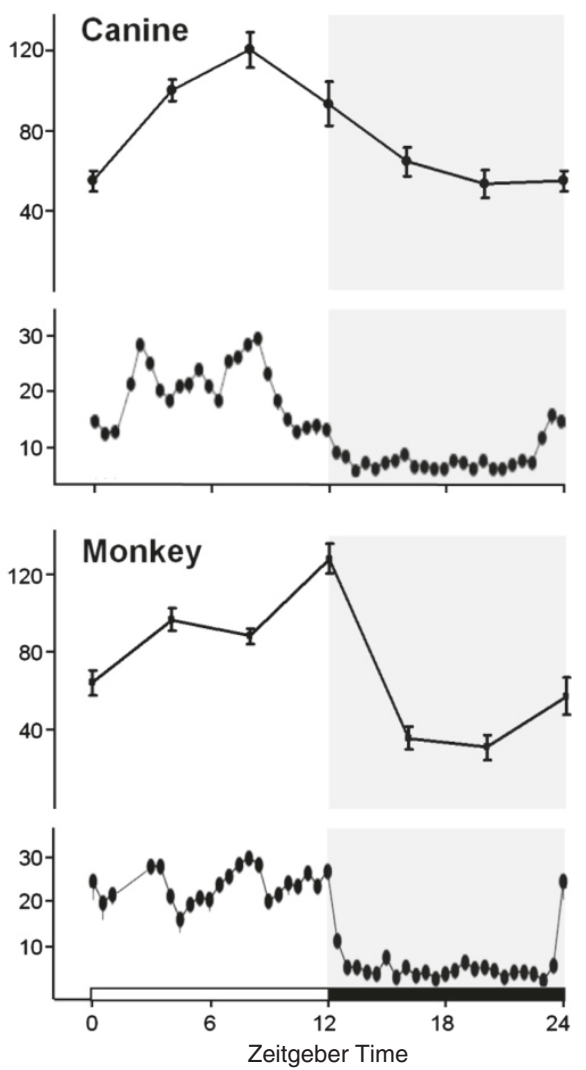

Figure 1 Active wake closely follows oscillating OX-A levels across preclinical species. The time course of OX-A levels in CSF and active wake were highest during the dark phase in nocturnal rodents (A) and during the light phase in diurnal species (B). Mean OX-A levels and time spent in active wake are plotted \pm standard error of the mean (SEM) over a 24-h period (dark period shaded) for 6-h and 30-min intervals, respectively. OX-A levels were determined by meso-scale immunoassay at 6-h time points in mice $(n=3 ; 50$ pooled CSF samples each), rats ( $n=8$ samples each), dogs ( $n=8$ samples each), and rhesus monkeys ( $n=8$ samples for ported animals, each). Mean time in active wake under baseline conditions was determined by EEG from telemeterized mice ( 6 days, $n=7)$, rats ( 6 days, $n=7)$, dogs ( 10 days, $n=6)$, and rhesus monkeys (5 days, $n=7)$.

to the inactive phase; namely, diminished active wake, increased slow wave sleep (SWS), and small fluctuations in REM sleep.

\section{DORA-induced efficacy occurs at $\mathrm{OX}_{2} \mathrm{R}$ occupancies exceeding $65 \%$}

A dose response for DORA-12, a structural analog of suvorexant, was evaluated in rat PSG studies to determine the relationship between sleep-promoting efficacy as measured by active wake reduction and $\mathrm{OX}_{2} \mathrm{R}$ occupancy. Dose-dependent attenuation of active wake was observed with DORA-12 (Figure 3A), which also resulted in corresponding increases in non-REM and REM sleep. Sleep-promoting efficacy induced by each dose of DORA-12 was quantified as a percent change in active wake relative to the vehicle-induced response over $2 \mathrm{~h}$ following treatment.
Separately, the relationship between $\mathrm{OX}_{2} \mathrm{R}$ occupancy relative to plasma exposure was determined by administering DORA-12 intravenously (i.v.) over a range of doses to transgenic rats expressing human $\mathrm{OX}_{2} \mathrm{R}$ to determine a full occupancy curve over a wide range of plasma concentrations in order to define the maximal occupancy against which raw occupancy values could be normalized. This relationship was then used to determine the $\mathrm{OX}_{2} \mathrm{R}$ occupancy in PSG experiments from measured plasma concentrations. The maximum plasma concentration $\left(\mathrm{C}_{\max }\right)$ observed in satellite animals dosed in parallel with those used in PSG experiments were used for these analyses since $C_{\max }$ occurs during the first two hours after treatment. Increased $\mathrm{OX}_{2} \mathrm{R}$ occupancy, achieved at higher doses, was accompanied by progressively greater attenuation of active wake (Figure 3B). This same pattern was also observed for suvorexant and 


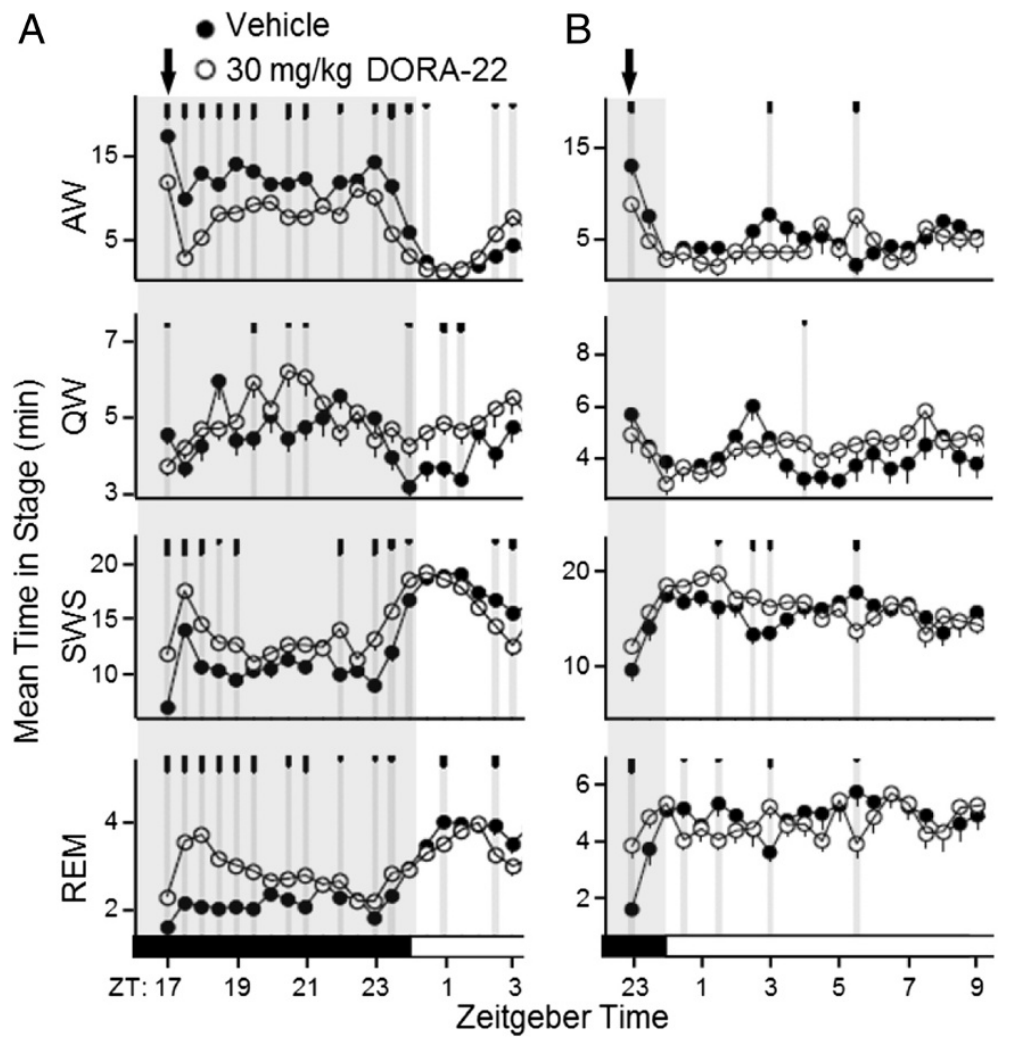

Figure 2 Sleep-promoting effects of DORA-22 in normal rats are diminished during the inactive phase. Vehicle (20\% Vitamin E TPGS, p.o.) and DORA-22 (30 mg/kg) were administered to rats during the mid-active phase (arrow, ZT 17:00; $\mathrm{n}=13)(\mathbf{A})$ or $1 \mathrm{~h}$ before the inactive phase (arrow, ZT 23:00; $n=8$ ) (B) in a balanced cross-over design. Values represent mean time in sleep stage over 30-min intervals over 3 days of consecutive treatment. Gray shading denotes the dark or active period. AW, active wake; QW, quiet wake. Time points at which significant differences exist between vehicle and DORA-22 responses are indicated by gray vertical lines and tick marks (short, medium, long marks: $P<0.05$, $0.01,0.001$, respectively).

structurally distinct compounds such as MK-6096 and DORA-22. Generally, compound-induced attenuation of active wake became salient and significant at $\mathrm{OX}_{2} \mathrm{R}$ occupancies between 63 and 83\%. While 0.3 and $1 \mathrm{mg} / \mathrm{kg}$ doses of DORA-12 marginally reduced active wake, this change became highly significant at $3 \mathrm{mg} / \mathrm{kg}$, where plasma levels reached $0.20 \mu \mathrm{M}$, corresponding to $83 \%$ $\mathrm{OX}_{2} \mathrm{R}$ occupancy (Figure 3, Table 1). For comparison, efficacy as determined by active wake reduction, plasma exposure, and $\mathrm{OX}_{2} \mathrm{R}$ occupancy in rats are presented for each dose of suvorexant and DORA-12 in Table 1.

It was previously shown that suvorexant attenuated active wake in dogs in a dose-dependent manner with corresponding increases in non-REM and REM sleep: the effects of $1 \mathrm{mg} / \mathrm{kg}$ on active wake were observed for up

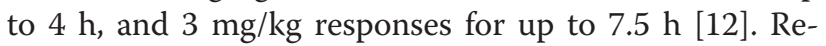
examination of the time course of plasma exposures indicated that suvorexant efficacy was observed at time points when plasma concentrations were in excess of $0.342 \mu \mathrm{M}$ (Figure 4A), a plasma exposure corresponding to $65.7 \% \mathrm{OX}_{2} \mathrm{R}$ occupancy calculated from rat occupancy values normalized for both rat and dog unbound plasma values (1.4 and 1.0\%, respectively). Time points showing active wake reduction following administration of suvorexant (1 and $3 \mathrm{mg} / \mathrm{kg}$ ) coincided with plasma exposures that were calculated to result in $\geq 65 \% \mathrm{OX}_{2} \mathrm{R}$ occupancy (Figure 4B), consistent with the range of effective occupancy observed in rats.

\section{$\mathrm{OX}_{2} \mathrm{R}$ binding kinetics contribute to the timing of DORA receptor occupancy}

To determine the influence of $\mathrm{OX}_{2} \mathrm{R}$ binding kinetics on receptor occupancy and sleep-promoting efficacy, the time course of in vivo effects in response to DORA-12 was compared with that of almorexant, a compound known to exhibit exceedingly slow dissociation from $\mathrm{OX}_{2} \mathrm{R}$. Almorexant is well documented to have slow binding kinetics relative to other DORAs $[18,23]$. Depending upon the method and competing ligand used, the $\mathrm{T}_{1 / 2}$ of almorexant for association with $\mathrm{OX}_{2} \mathrm{R}$ ranges from 28 to $162 \mathrm{~min}$ and from 70 to $268 \mathrm{~min}$ for dissociation (the later values obtained in current experiments comparing 6 different DORAs in Table 2). DORA-12 (30 mg/kg) and almorexant 

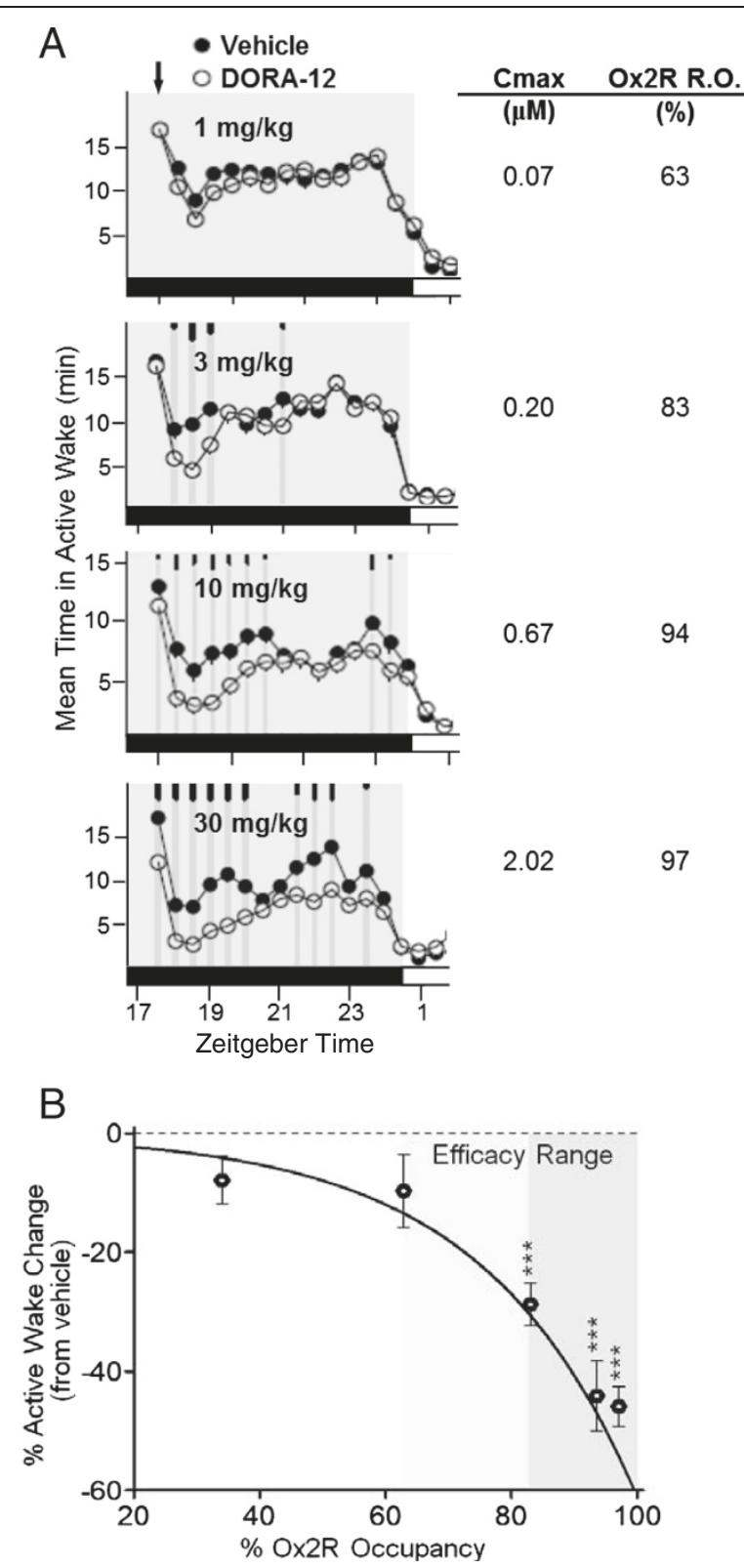

Figure 3 Sleep efficacy of DORA-12 in rats is associated with $\mathrm{OX}_{2} \mathrm{R}$ occupancies between 63 and $83 \%$. A. Attenuation of mean time in active wake in rats in response to DORA-12 $(1 \mathrm{mg} / \mathrm{kg}[\mathrm{n}=$ 14], $3 \mathrm{mg} / \mathrm{kg}[\mathrm{n}=14], 10 \mathrm{mg} / \mathrm{kg}[\mathrm{n}=8]$, and $30 \mathrm{mg} / \mathrm{kg}[\mathrm{n}=14)$ relative to vehicle (20\% Vitamin E TPGS, p.o.) dosed mid-active phase (arrow). Gray shading, dark period. Time points at which significant differences exist between vehicle and DORA-12 responses are indicated by gray vertical lines and tick marks (short, medium, long marks: $P<0.05,0.01,0.001$, respectively). Maximum plasma values $\left(C_{\max }\right)$ and corresponding occupancy values determined in satellite animals are listed to the right. $\mathbf{B}$. The mean percent change $( \pm$ SEM) in active wake quantified from individual PSG recordings from ' $A$ ' versus percent $\mathrm{OX}_{2} \mathrm{R}$ occupancy determined in rats (satellite animals). Light and dark shading indicates potential and definitive occupancy ranges. ${ }^{* * *} \mathrm{P}<0.001$ (t-test) difference in percent active wake change versus baseline.
$(100 \mathrm{mg} / \mathrm{kg})$ were administered both during the mid-active phase and just prior to the inactive phase, a therapeutically relevant dosing time, in rats. DORA-12 significantly attenuated active wake for approximately $6 \mathrm{~h}$ following dosing during the active phase and up to $3.5 \mathrm{~h}$ after treatment at the inactive phase onset $(\mathrm{P}<0.05$ through 0.001 ; see Figure 5A, upper panels). Almorexant-dependent reductions in active wake were seen for up to $7.5 \mathrm{~h}$ after treatment during the active phase and for up to $11 \mathrm{~h}$ following inactive-phase treatment (Figure 5B, upper panels).

Plasma and CSF levels of DORA-12 and almorexant, as well as $\mathrm{OX}_{2} \mathrm{R}$ occupancy were determined in satellite rats following treatment at the onset of the inactive phase. As seen in Figure 5A (lower panels), DORA-12 plasma and CSF levels began to fall immediately after dosing, with corresponding decreases in $\mathrm{OX}_{2} \mathrm{R}$ occupancy to $77 \%$ of maximum at $8 \mathrm{~h}$, coincident with the cessation of sleep-promoting effects. $\mathrm{OX}_{2} \mathrm{R}$ occupancy by almorexant, however, remained elevated at $10 \mathrm{~h}$, even though levels within the CSF were undetectable at this time point (Figure 5B, lower panels). The persistence of $\mathrm{OX}_{2} \mathrm{R}$ occupancy by almorexant despite disappearing levels of the compound in the plasma and CSF is consistent with its extremely slow receptor-binding kinetics relative to other DORAs including suvorexant, MK6096, DORA-22 and SB-649868 (Table 2). Together these results indicate that binding kinetics have the capacity to influence receptor occupancy and sleep promoting efficacy, particularly for compounds with excessively slow kinetic parameters.

\section{Next-day sleep, qEEG, and quantitative effects in rhesus monkeys}

To evaluate the potential for both GABA-A receptor modulators and DORA-22 to promote sleep through the resting phase and into the subsequent active phase, rhesus monkeys were administered these compounds $2 \mathrm{~h}$ before lights out. The doses, diazepam at $10 \mathrm{mg} / \mathrm{kg}$, eszopiclone at $10 \mathrm{mg} / \mathrm{kg}$, and DORA-22 at $30 \mathrm{mg} / \mathrm{kg}$, were selected based on their similar potential to promote sleep following active-phase dosing. Quantified over $2 \mathrm{~h}$, these treatments have previously been found to attenuate active wake by $38.4,55.0$, and $40.1 \mathrm{~min}$ relative to vehicle, respectively [24].

Diazepam, eszopiclone, and DORA-22 produced characteristic plasma-exposure profiles (Figure 6A). The anxiolytic diazepam exhibited a peak at $1.0 \mathrm{~h}(775 \mathrm{nM})$, eszopiclone induced a more rapid $\mathrm{C}_{\max }$ at $0.5 \mathrm{~h}(1680$ $\mathrm{nM})$, and DORA-22 a more delayed exposure profile (134 $\mathrm{nM}$ at $2 \mathrm{~h}$ ). All three compounds significantly attenuated active wake in the $2 \mathrm{~h}$ after dosing before the onset of the inactive phase (Figure 6B). Unlike eszopiclone and DORA-22, diazepam significantly attenu- 
Table 1 Efficacy as measured by active wake reduction by suvorexant and DORA-12 relative to plasma exposure and $\mathrm{OX}_{2} \mathrm{R}$ exposure in rats

\begin{tabular}{|c|c|c|c|c|}
\hline Compound & Dose $(\mathrm{mg} / \mathrm{kg})$ & Plasma (nM) & $\mathrm{OX}_{2} \mathrm{ROcc}^{\mathrm{a}}\left(\% \mathrm{max}^{\mathrm{b}}\right)$ & Active wake reduction ${ }^{c} \%$ \\
\hline \multirow[t]{3}{*}{ Suvorexant } & 10 & 1600.0 & 92.6 & $-29.0^{* * *}$ \\
\hline & 30 & 2100.0 & 94.3 & $-79.6^{* *}$ \\
\hline & 100 & 5100.0 & 97.6 & $-79.9^{* *}$ \\
\hline \multirow[t]{5}{*}{ DORA-12 } & 0.3 & 20.2 & 34.0 & -7.9 \\
\hline & 1 & 67.4 & 62.8 & -9.7 \\
\hline & 3 & 202.2 & 83.0 & $-28.8^{* * *}$ \\
\hline & 10 & 674.0 & 93.9 & $-44.2^{* * *}$ \\
\hline & 30 & 2022.0 & 97.1 & $-45.9^{* * *}$ \\
\hline
\end{tabular}

${ }^{\mathrm{a} O c c}$, occupancy.

${ }^{b}$ Normalized occupancy was determined over a range of doses and fit to a one-sided binding hyperbolic curve to determine the maximum occupancy. OX ${ }_{2} \mathrm{R}$ occupancies corresponding to plasma values at indicated doses were calculated based on the normalized curve for each compound.

${ }^{c}$ Mean percent change in active wake relative to vehicle in the $2 \mathrm{~h}$ following treatment $\left(*^{* *}, *^{* *}, \mathrm{p}<0.01,0.001\right.$, population t-test).

ated active wake at time points $7.5 \mathrm{~h}$ into the inactive phase and $3 \mathrm{~h}$ into the subsequent active phase. Despite the presence of measurable eszopiclone and DORA-22 plasma levels $17 \mathrm{~h}$ after treatment, no consistent attenuation of active wake was observed in response to either compound the morning after treatment.

Quantitative EEG analysis performed coincident with PSG revealed time-dependent and qualitative differences

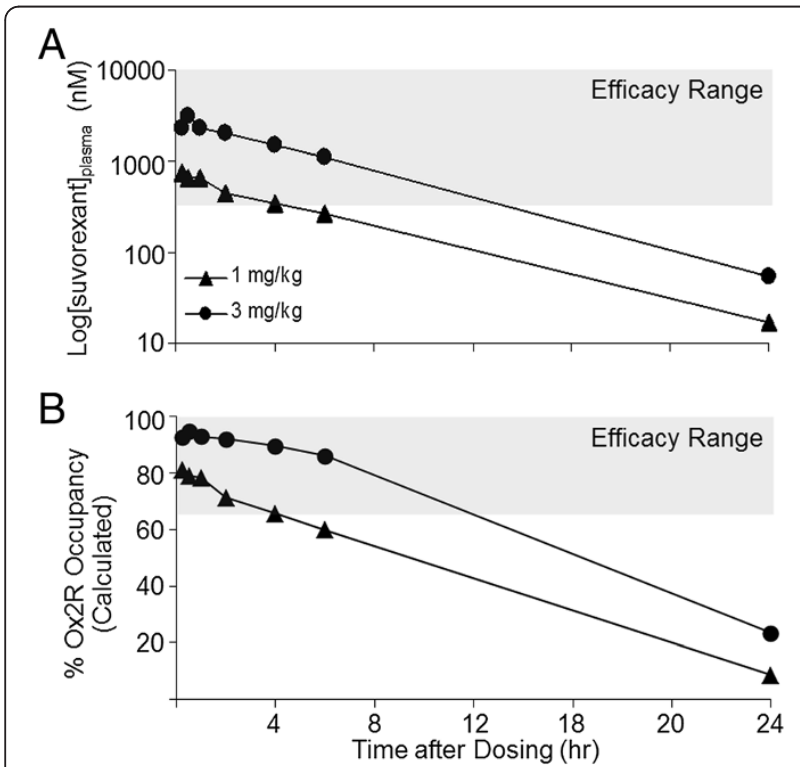

Figure 4 Suvorexant efficacy in dogs corresponds to plasma exposures $>342 \mathrm{nM}$ and $\mathrm{OX}_{2} \mathrm{R}$ occupancies $>65 \%$. A. Suvorexant levels in satellite animals treated with suvorexant (1 or $3 \mathrm{mg} / \mathrm{kg}$; p.o. in $20 \%$ Vitamin E TPGS) ( $n=3$, each time point). B. Calculated $\mathrm{OX}_{2} \mathrm{R}$ occupancy based on rat occupancy values, and normalized for free fraction of compound in rat (1.4\%) and dog (1\%). Gray shading indicates time points at which active wake was significantly attenuated in dogs treated with suvorexant (1 or $3 \mathrm{mg} / \mathrm{kg}$ ), the plasma and occupancy range at which efficacy has been observed [12]. between the effects of these compounds that were not evident in measurements of active wake. All three compounds increased delta frequency qEEG power in advance of the normal increase in delta power observed during the resting phase after administration of vehicle (Figure 6C, bottom panels). However, both diazepam and eszopiclone increased high-frequency gamma power and substantially decreased theta power throughout the inactive period, while DORA-22 had essentially no effect on these measures (Figure 6C, top and middle panels). The effects of diazepam persisted into the subsequent active period while eszopiclone-induced qEEG changes ceased abruptly upon lights on (at which point cognitive tests were performed). The relevance of compoundinduced qEEG changes occurring during cognitive testing intervals is currently unknown.

In order to better understand the consequences of compound-induced sleep and qEEG effects that persist though the inactive period, cognitive memory and attention parameters were evaluated in the same rhesus monkeys, the morning after treatment. Memory was evaluated in the delayed match to sample (DMS) task performed at lights on (14 h after dosing), while attention was evaluated in the serial choice retention time (SCRT) test administered $2 \mathrm{~h}$ later (16 h after dosing; see Figure $6 \mathrm{C}$, bottom panels, $\mathrm{D}$ and $\mathrm{C}$ time points). Significant deficits in recognition memory, as assessed by DMS, were observed the morning after treatment with diazepam $(10 \mathrm{mg} / \mathrm{kg})$ but not following eszopiclone $(10 \mathrm{mg} / \mathrm{kg})$ or DORA-22 $(30 \mathrm{mg} / \mathrm{kg})$ relative to their respective vehicle treatments (Figure 6D). These results are consistent with diazepam-dependent active wake attenuation persisting into the active period. Despite the presence of measurable levels of this DORA-22 three hours after the DMS task was performed (Figure 6A; 61 $\mathrm{nM}$ ), no attenuation of in performance was observed. In SCRT, both diazepam and eszopiclone elicited significant 
Table 2 Orexin 2 receptor binding kinetic parameters for DORAs

\begin{tabular}{|c|c|c|c|c|c|}
\hline Compound & $K_{d}(n M)$ & $T_{1 / 2}$ ON (min) & $\mathrm{K}_{\mathrm{ON}}\left(\mathrm{mol}^{-1} \cdot \mathrm{min}^{-1}\right)$ & $\mathrm{T}_{1 / 2}$ OFF (min) & $\mathrm{K}_{\mathrm{OFF}}\left(\min ^{-1}\right)$ \\
\hline Almorexant & 0.048 & $162^{a}$ & $1.58 \times 10^{7}$ & 268 & $2.696 \times 10^{-3}$ \\
\hline Suvorexant & 0.401 & 80.1 & $7.63 \times 10^{6}$ & 89.4 & $7.784 \times 10^{-3}$ \\
\hline DORA-12 & 0.157 & 57.5 & $2.77 \times 10^{7}$ & 232 & $3.154 \times 10^{-3}$ \\
\hline MK-6096 & 0.338 & 62.9 & $1.69 \times 10^{7}$ & 118 & $6.754 \times 10^{-3}$ \\
\hline DORA-22 & 0.834 & 24.7 & $9.19 \times 10^{6}$ & 37.8 & $1.878 \times 10^{-2}$ \\
\hline SB-649868 & 0.163 & 37.0 & $2.56 \times 10^{7}$ & 57.0 & $1.258 \times 10^{-2}$ \\
\hline
\end{tabular}

${ }^{a}$ Almorexant $T_{1 / 2}$ ON represents an underestimate as almorexant was applied at concentrations 3-fold above its $\mathrm{K}_{d}$ in order to measure its kinetics alongside other DORAs.

$\mathrm{K}_{\mathrm{d}}$, binding constant; $\mathrm{K}_{\mathrm{OFF}}$, dissociation constant; $\mathrm{K}_{\mathrm{ON}}$, association constant; $\mathrm{T}_{1 / 2}$ OFF, half-life off-rates; $\mathrm{T}_{1 / 2} \mathrm{ON}$, binding half-life.
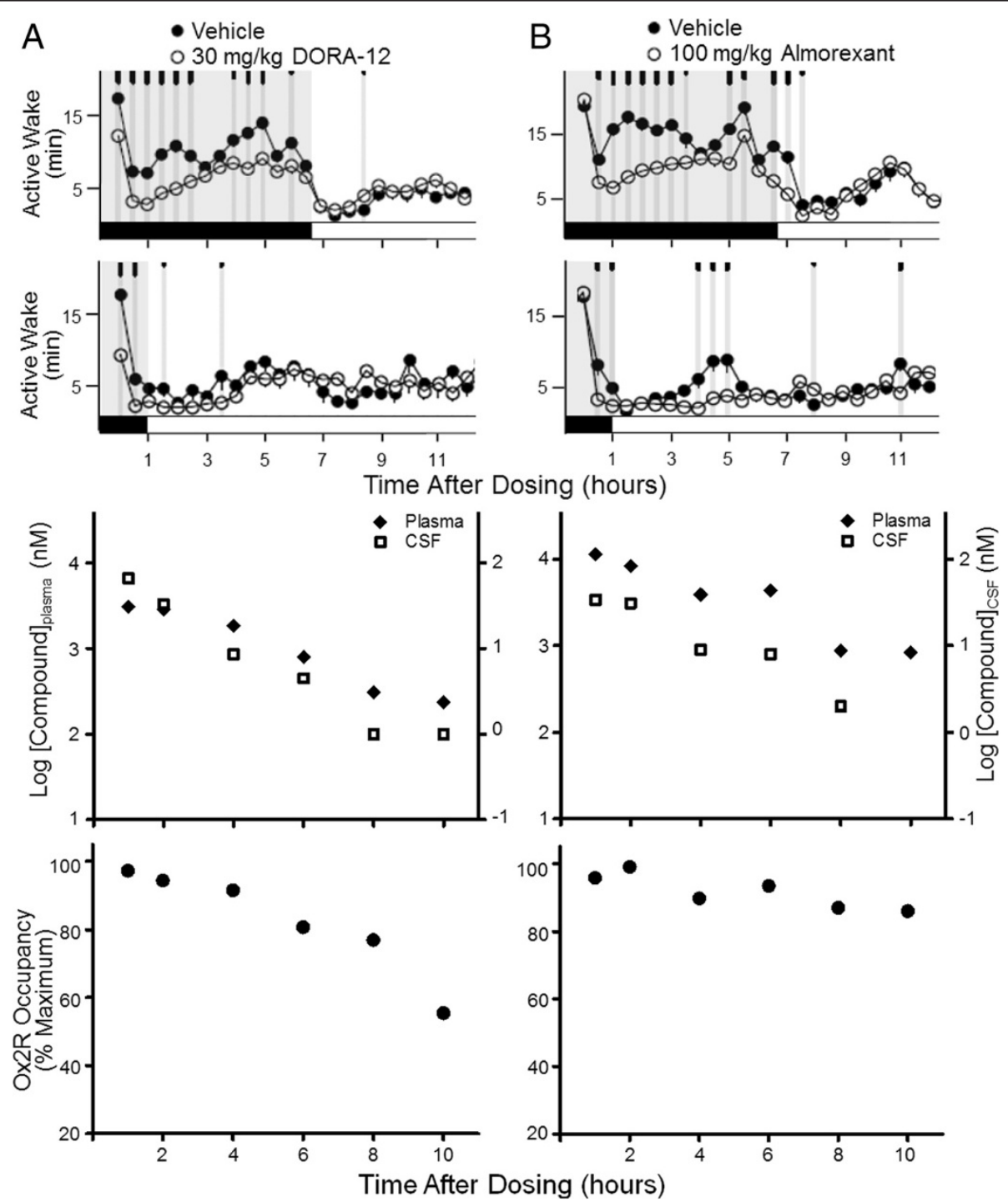

Figure 5 Time course of DORA-12 and almorexant $\mathrm{OX}_{2} \mathrm{R}$ occupancy and efficacy in rats. A (upper panels). The time course of DORA-12 (30 mg/kg) effects on active wake was determined in rats by telemetry PSG relative to vehicle (20\% Vitamin E TPGS, p.o.) following treatment in active $(n=14)$ or inactive phase $(n=7)$. Time points at which significant differences exist between vehicle and DORA-12 responses are indicated by gray vertical lines and tick marks (short, medium, long marks: $\mathrm{P}<0.05,0.01,0.001$, respectively). B (upper panels). Effects of almorexant $(100 \mathrm{mg} / \mathrm{kg})$ on active wake relative to vehicle following treatment in active $(n=14)$ or inactive phase $(n=14)$. Lower panels. Plasma and CSF levels as well as $\mathrm{OX}_{2} \mathrm{R}$ receptor occupancy of DORA-12 (A) and almorexant (B) following inactive phase treatment (one male, one female animal per time point). Plasma, CSF, and occupancy levels were determined in the same animals, in satellite to PSG experiments. 


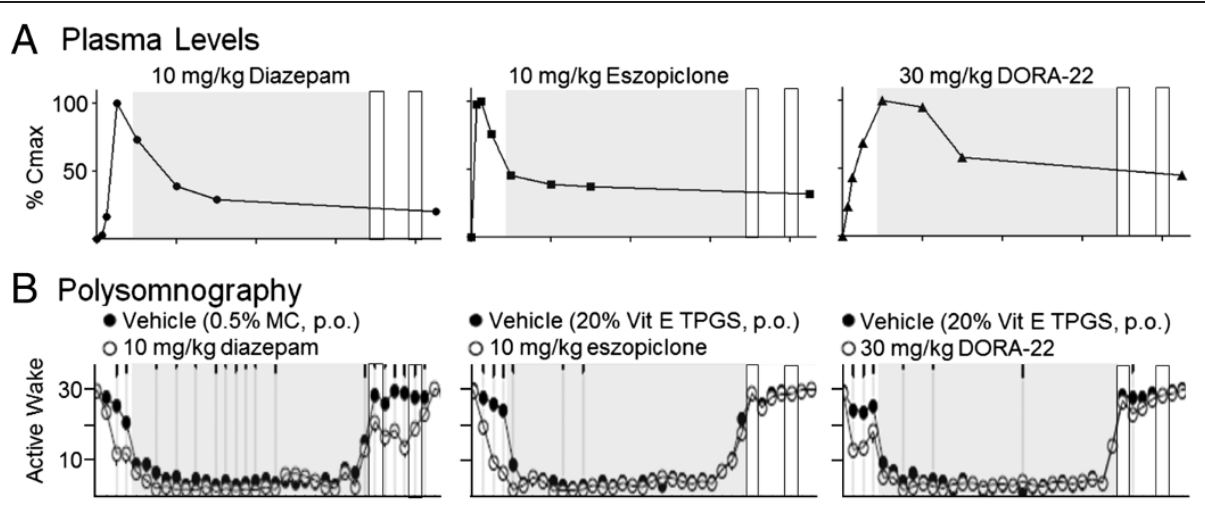

\section{C qEEG Power}
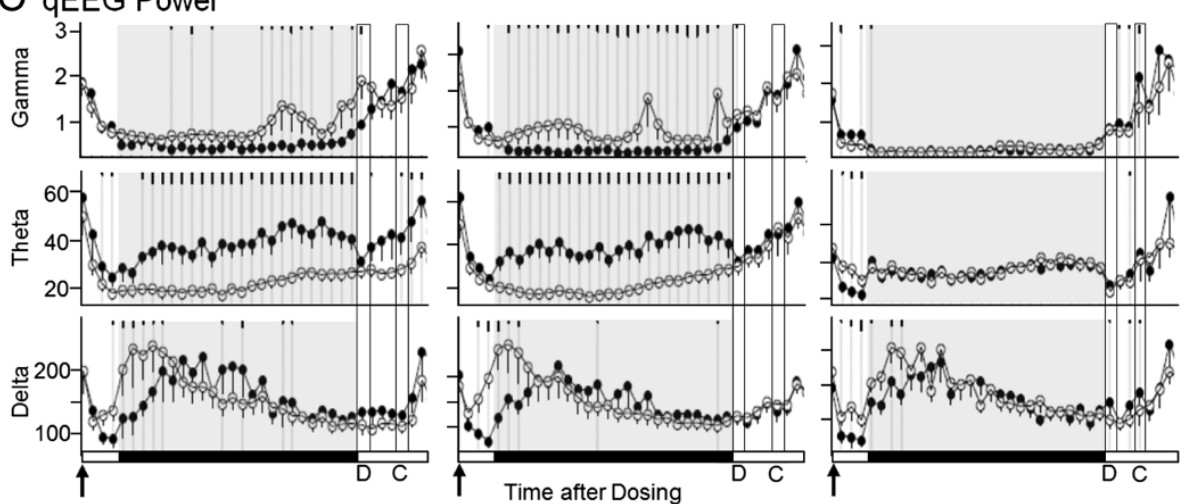

D Next Day Memory

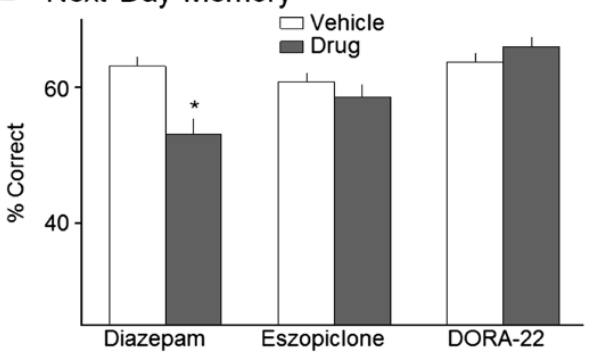

E Next Day Attention

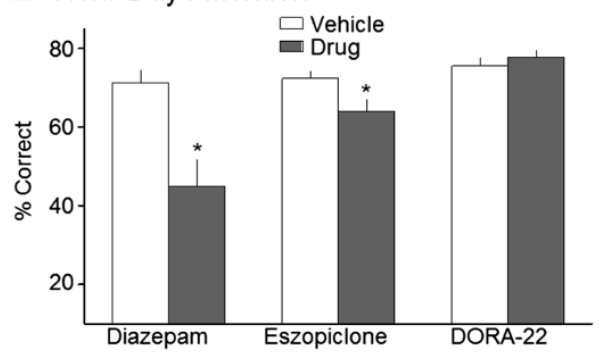

Figure 6 Diazepam and eszopiclone, but not DORA-22, exhibit next-day effects impacting cognitive performance in monkeys. Monkeys were treated (arrow) with sleep-promoting doses $2 \mathrm{~h}$ before the 12-h dark/inactive phase (gray shading): diazepam, $10 \mathrm{mg} / \mathrm{kg}$, p.o. in $0.5 \%$ methylcellulose; eszopiclone, 10 mg/kg, in 20\% Vitamin E TPGS; DORA-22, 30 mg/kg, in 20\% Vitamin E TPGS. Memory and attention were evaluated by DMS (D) and SCRT (C) tasks 14 and $16 \mathrm{~h}$ after dosing, respectively. A. Time course of plasma levels after dosing $(0,0.25,0.5,1,2,4$, $6,17 h ; n=2$, diazepam and eszopiclone; $n=3$, DORA-22 [17 $h, n=8])$. Normalized plasma levels relative to maximum $\left(C_{\max }\right.$ : diazepam 775 nM [1 h]; eszopiclone $1680 \mathrm{nM}$ [0.5 h]; DORA-22 $134 \mathrm{nM}$ [2 h]) compare compound levels on the same y-axis scale. B. Mean time in active wake (+ SEM) determined by polysomnography in 30-min intervals after treatment (vehicle, closed symbols; compound, open symbols). Significant differences versus vehicle are indicated by gray vertical lines and tick marks (short, medium, long: $\mathrm{P}<0.05,0.01,0.001$, respectively). C. Mean qEEG power in gamma $(35-100 \mathrm{~Hz})$, theta $(4-8 \mathrm{~Hz})$, and delta $(0.5-4 \mathrm{~Hz})$ frequency bands following treatment. D. DMS measure of memory at $14 \mathrm{~h}$ after treatment. Data are mean proportions of completed trials during which a correct choice was made ( $\mathrm{SEM} ; \mathrm{n}=16,16$, and 15, respectively). Random responding, 25\%. Significant differences from vehicle: ${ }^{*} \mathrm{P}<0.05$ (repeated measures ANOVA). E. SCRT evaluation of attention at $16 \mathrm{~h}$ after treatment. Data are the mean proportions of completed trials during which a correct choice was made following short duration cues ( $\mathrm{SEM} ; \mathrm{n}=16,16$, and 5, respectively). Random responding, $10 \%$. Significant differences from vehicle: ${ }^{*} P<0.05$.

deficits in the percentage of correct responses to cues of the shortest duration relative to vehicle-treated controls $(\mathrm{P}<0.05$ for both) (Figure 6E). In contrast, deficits in next-day attention were not observed with DORA-22.

\section{Suvorexant exposure time course in humans}

Plasma samples obtained in an Phase 1 clinical evaluation of suvorexant exhibited a common exposure profile, with a time to maximum plasma concentration 
$\left(\mathrm{T}_{\max }\right)$ of $3 \mathrm{~h}$ or less (Figure 7$)$. Human free plasma levels of suvorexant sufficient for $65 \% \mathrm{OX}_{2} \mathrm{R}$ occupancy were calculated based on extensive transgenic rat occupancy data and normalized for free fraction (rat: 1.4\%; human: $1.0 \%)$. The human plasma concentration of suvorexant calculated to correspond to $65 \% \mathrm{OX}_{2} \mathrm{R}$ occupancy is $0.33 \mu \mathrm{M}$ (free + bound). Observed clinical suvorexant mean plasma concentrations fell below the levels predicted to correspond to $65 \% \mathrm{OX}_{2} \mathrm{R}$ occupancy, where sleep-promoting efficacy is predicted, by the $8 \mathrm{~h}$ post-dose time point for both the 10 and $20 \mathrm{mg}$ therapeutic doses. Together this analysis indicates that the sleep promoting effects of suvorexant would not be expected to persist into subsequent waking hours at therapeutic doses less than $20 \mathrm{mg}$.

\section{Discussion}

Timing of the pharmacodynamic efficacy of drugs targeting insomnia is critical to promote sleep maintenance throughout the resting phase and to avoid undesired next-day effects such as residual drowsiness upon waking. GABA-A receptor modulators, the current standard of care for insomnia, act by potentiating the activity of endogenous neurotransmitters and have a low threshold of receptor occupancy for in vivo efficacy [25]. This low threshold allows GABA-A receptor modulators to promote sleep maintenance during the resting period, but also represents a challenge to terminate their agonist activity prior to ensuing wake periods to avoid next-day effects. DORAs provide an alternative mechanism for the treatment of insomnia by inhibiting the wakepromoting activity of orexin neuropeptides. As such, a higher percentage of receptor occupancy is required to

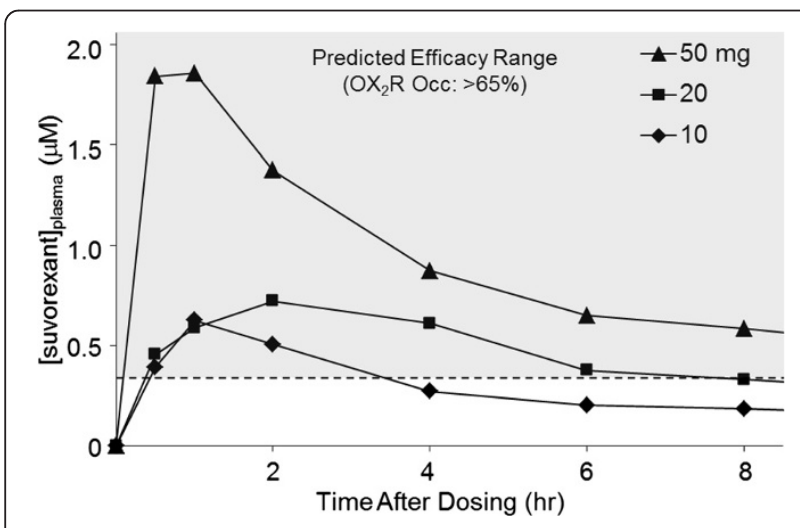

Figure $7 \mathrm{OX}_{2} \mathrm{R}$ occupancy by suvorexant sufficient for sleeppromoting efficacy: restricted to $\mathbf{8} \mathrm{h}$ following treatment. The time courses of plasma levels of suvorexant in humans collected in Phase 1 clinical trials following administration of suvorexant (indicated doses) are shown relative to the plasma values $(0.33 \mu \mathrm{M})$ calculated to correspond to the exposure required for $65 \% \mathrm{OX}_{2} \mathrm{R}$ occupancy (dashed line). The gray shaded area represents the predicted efficacy range based upon this value. occ, occupancy. block the effect of the endogenous peptide ligand in order to promote sleep. The current studies evaluate the pharmacokinetic and receptor-binding properties that contribute to the timing of $\mathrm{OX}_{2} \mathrm{R}$ receptor occupancy and in vivo efficacy to define the potential of the DORA mechanism of action to promote sleep maintenance during the resting phase while avoiding next-day residual effects.

The capacity of orexin receptor antagonists to block orexin-induced arousal at a given time of day is dependent upon endogenous orexin neuropeptide levels. This signal window was defined by evaluating OX-A levels in two nocturnal and two diurnal species and was correlated with sleep/wake cycles in which the highest levels of wakefulness were observed during the active phase and the lowest levels during the inactive phase. As predicted, the largest observable sleep-promoting effects of DORAs in rats were greatest during the active phase when orexin levels were highest, and effects were diminished during the inactive phase, consistent with previous studies of other DORAs [10-12]. Importantly, effects of DORAs detected during the resting phase were an augmentation of normal sleep parameters, including further attenuation of active wake, promotion of SWS, and REM sleep that was either unchanged (as seen in the present studies) or improved [10,11]. Previous analysis of DORA-22-induced changes in qEEG spectral power during the inactive phase found only minimal changes in frequency distribution relative to vehicle treatment, indicating minimal disruption of $\mathrm{qEEG}$ patterns during the resting phase [20]. These results were supported by the observed effects of DORA-22 on resting-phase qEEG in rhesus monkeys where gamma and theta activity remained unchanged while delta frequency power was augmented from the pattern normally seen in vehicletreated animals (see Figure $6 \mathrm{C}$ ). In stark contrast, the effects of the GABA-A receptor modulators diazepam and eszopiclone increased high frequency gamma power and suppressed theta activity in directions that were diametrically opposed to those normally observed during the resting phase of vehicle-treated animals. These results are consistent with disrupted sleep-stage-specific qEEG spectral patterns induced by GABA-A receptor modulators, observed previously in rats [20] and humans [15]. The relatively minimal effects of DORA-22 on both sleep and qEEG spectral patterns further indicate that DORAs selectively block orexin-mediated arousal, which is at its lowest during the normal resting phase.

The etiology of insomnia is not well understood at the neurotransmitter or neuronal pathway level, and changes in orexin levels have yet to be demonstrated as a cause of insomnia. As such, translatable preclinical models for insomnia have not been developed and the studies performed in the current work only mimic the normal, 
or healthy condition where orexin levels are diminished during the normal inactive phase. However, orexin levels have been observed to increase with wake-related motor activity associated with forced swimming in rats [26], in patients with restless legs syndrome [27], and are diminished in narcoleptic patients based on examination of CSF levels derived from lumbar collection [28]. Persistent and significant reductions in wakefulness have been observed during the resting phase of insomnia patients in response to suvorexant treatment [17] and to SB-649868 in a situational model of insomnia [15]. These clinical observations suggest that DORAs are effective in reversing elevated orexin signaling present in insomnia patients.

This work in rats and dogs demonstrates that salient sleep promotion by DORAs is achieved at plasma levels necessary for $\mathrm{OX}_{2} \mathrm{R}$ occupancy to exceed a threshold of 65 to $80 \%$ as calculated based on the transgenic rat model. Sleep promotion in dogs was observed at times during which suvorexant levels were sufficient for $\mathrm{OX}_{2} \mathrm{R}$ occupancies in excess of $65 \%$. In rats, highly significant active wake attenuation in the $2 \mathrm{~h}$ following dosing of DORA-12 occurred at plasma concentrations corresponding to occupancies of $83 \%$ in transgenic animals, while a trend toward active wake reduction (-9.7\%) was seen at an occupancy of $63 \%$ occupancies did not reach significance in this experiment. While it remains possible that variation in expression in transgenic animals expressing the human receptor may have contribute to slightly different levels of receptor occupancy, the similar in vitro potency of DORA-12 in humans and rats (FLIPR $\mathrm{K}_{\mathrm{b}}=19 \mathrm{nM}$ and $25 \mathrm{nM}$, respectively; unpublished observations) indicates that the results in transgenic animals were a reasonable facsimile of receptor binding in genetically unmodified animals. The 65 to $80 \%$ occupancy range is consistent with prior studies measuring $\mathrm{OX}_{2} \mathrm{R}$ occupancy by orexin antagonists in specific brain regions. Although efficacy thresholds were not explicitly defined, Dugovic et al. (2009) did not observe almorexant efficacy at $78 \%$ occupancy, and appeared to see significant changes at occupancies above 89\% [29], while Morairty et al. (2012) saw differential sleep drop-off when $\mathrm{OX}_{2} \mathrm{R}$ occupancies diminished from 75 to $63 \%$ [30]. Moreover, effective occupancy thresholds of 65 to $90 \%$ for antagonists targeting CNS G protein coupled receptors such as neuroleptics for D2-like receptors, have been found previously [31,32]. Comparisons between methods, however, should be made with caution since different approaches utilizing varying assay incubation times coupled with differing compound offrates can influence raw occupancy measurements. Importantly, the pattern of increased $\mathrm{OX}_{2} \mathrm{R}$ occupancy in rats alongside dose-dependent attenuation of active wake with structurally distinct DORAs observed herein and in other published studies $[10,12,18]$ indicates that the occupancy threshold required for efficacy is a general property of orexin antagonism and is not compound dependent. These findings illustrate the importance of mechanism-dependent differences in receptor occupancy thresholds in determining the timing of sleep-promoting efficacy of GABA-A receptor modulators relative to DORAs. Ideally, insomnia treatments are expected to normalize the elevated levels of active wake experienced during disrupted sleep that are characteristic of insomnia during the resting period (Figure 8A). GABA-A receptor modulators, including diazepam (a benzodiazepine receptor modulator, BzRM) as well as zolpidem and eszopiclone (non-BzRMs), exhibit in vivo efficacy at a mean GABA-A receptor occupancy of $27 \%$. Low levels of receptor engagement are likely due to the receptor activation mechanism of these compounds leading to amplification of cellular signaling [25]. This low threshold for efficacy presents a challenge to GABA-A receptor modulators to restrict their sleep-promoting effects to the inactive phase. GABA-A receptor occupancy by diazepam, an anxiolytic BzRM with a long $\mathrm{T}_{1 / 2}$, exceeds this occupancy threshold long into the subsequent active period at sleep-promoting doses. As a consequence, diazepam exhibits substantial residual effects (Figure $8 \mathrm{~B}$ ) in terms of both sedation and cognitive measures (see Figure 6). Non-BzRMs that have a shorter exposure $\mathrm{T}_{1 / 2}$ more rapidly exceed receptor occupancy thresholds sufficient for sleep promotion. However, depending on dosage, these non-BzRMs may not maintain sleep throughout the inactive period, resulting in early morning awakenings (Figure 8C). Identifying appropriate dosages that avoid residual effects but maintain restingphase efficacy is complicated by the additional non-sleeprelated effects of these compounds. In the current studies, eszopiclone-induced reductions in active wake were detectable for up to $6 \mathrm{~h}$ while qEEG effects were observed almost $14 \mathrm{~h}$ later and effects on attention for up to $16 \mathrm{~h}$ (see Figure 6).

In contrast, DORAs exhibit in vivo sleep effects at plasma exposures sufficient for $65 \% \mathrm{OX}_{2} \mathrm{R}$ occupancy, the higher level of receptor engagement being required to sufficiently block the activating effect of the orexin ligand (Figure 8D). This high occupancy threshold requires DORAs to maintain plasma concentrations sufficient to promote sleep maintenance throughout the normal resting period. At the same time, DORAs are less likely to exhibit next-day residual somnolence despite being present at measurable plasma levels due to the high receptor occupancy threshold required for sleep maintenance. The sleep-promoting effects of falling levels of the antagonist at the onset of the normal waking phase are also likely to be countered by accumulating levels of the endogenous orexin ligand, which might provide an even faster cessation of DORA-induced 


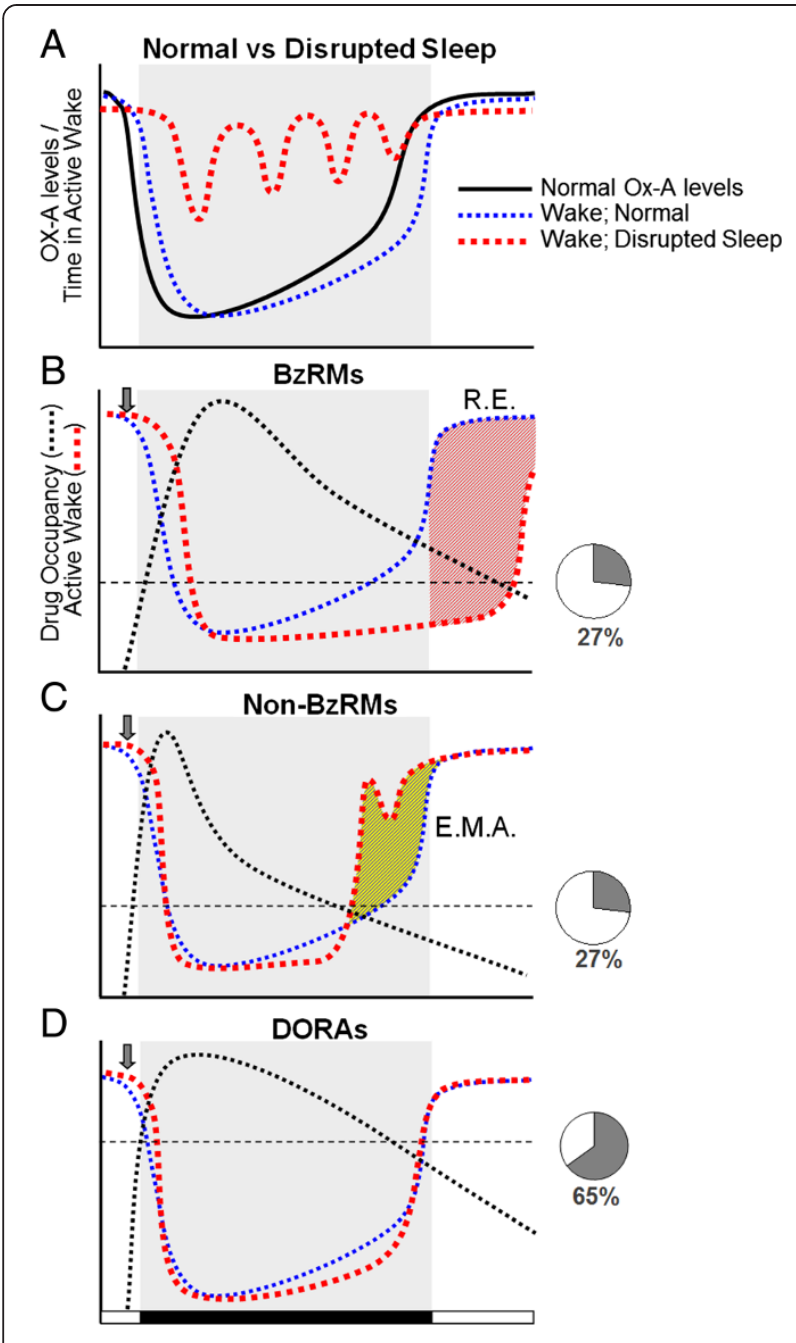

Figure 8 Conceptual model for DORA $\mathrm{OX}_{2} \mathrm{R}$ occupancy and efficacy based on pharmacokinetic and receptor-binding properties. A. Normal and disrupted sleep relative to OX-A levels (solid black line) during the human inactive period (gray shading). Wake during disrupted sleep (red dashed line) is punctuated by brief periods of wake after sleep onset, while normal sleep (blue dashed line) follows orexin levels. B. Time course of the sleep-promoting efficacy of benzodiazepinebased GABA-A receptor modulators (BzRMs). Following treatment (gray arrow), active wake diminishes as GABA-A receptor occupancy (black dotted line) exceeds that required for sleep efficacy, 27\% (horizontal black dashed line) [25]. Red hatched area, difference from normal active wake (blue dashed line). Residual effects (R.E.) during the subsequent waking period as compound levels sufficient for GABA-A receptor occupancy are exceeded following the normal 8-h resting period. $\mathbf{C}$. Efficacy time course of non-benzodiazepine GABA-A receptor modulators (non-BzRMs). GABA-A receptor occupancy (black dotted line) induced by sub-optimal doses of non-BzRMs are not sufficient to engage these receptors allowing early morning awakenings (E.M.A.). Yellow hatched area, difference from normal active wake (blue dashed line). D. DORAs, sufficiently engineered for optimal pharmacokinetic and receptor-binding kinetics, induce $\mathrm{OX}_{2} \mathrm{R}$ occupancies (black dotted line) sufficient to block the wake-promoting properties of orexin throughout the 8-h resting period and, given the high level of $\mathrm{OX}_{2} \mathrm{R}$ occupancy required for sleep-promoting efficacy, avoid residual effects persisting into the subsequent waking period even in the presence of moderate levels of compound exposure. somnolence due to the competitive nature of the antagonists and the relatively close $K_{i}$ values.

Unlike GABA-A receptor modulators, DORA-22 did not exhibit next-day residual effects in rhesus monkeys despite the presence of measurable plasma levels $17 \mathrm{~h}$ after dosing. DORA-22 did not impact next-day sleep, $\mathrm{qEEG}$, or cognitive measures as compound levels were insufficient to occupy $\mathrm{OX}_{2} \mathrm{R}$ above the necessary efficacy threshold. Diazepam, an anxiolytic with a long $\mathrm{T}_{1 / 2}$, promoted sleep throughout the normal resting period and into the subsequent active phase and also impacted memory and attention. Eszopiclone did not demonstrate next-day sleep effects or memory impairment; however, it did significantly impair attention as measured by SCRT. Although sleep effects did not persist with eszopiclone, qEEG spectral power changes were evident up to lights on/performance of DMS tasks. The effect of cognitive testing on qEEG measures is currently uncharacterized, and the effect of administering a treatment for insomnia in addition to cognitive testing on qEEG spectral power is even less certain. Direct compound effects may be one possible explanation for the next-day attention deficits found with eszopiclone, as measurable concentrations (535 nM) were reported $17 \mathrm{~h}$ after administration. Another possibility is that this attention deficit is a consequence of abnormal sleep occurring during the previous inactive phase. Sleep-stage disruption, particularly of REM sleep, which is thought to restore cognitive performance [33,34], may be responsible for potentiating this deficit. Eszopiclone induced substantial changes in gamma and theta qEEG spectral power relative to vehicle for the entire resting period - a result consistent with both suppressed REM sleep and disrupted sleep-stage-specific EEG spectral activity observed in previous studies $[15,20]$.

Conversely, the lack of qEEG spectral disruption by DORA-22 during the previous resting phase was associated with no such cognitive impairment. Currently, it is unclear whether the lack of cognitive impairment by DORA-22 is due to the promotion of unperturbed sleep or a lack of on-drug cognitive effects. Indeed, cognitive assessment of rhesus monkeys performed within $2 \mathrm{~h}$ following treatment indicated no impairment in DMS and SCRT tasks with DORA-22, but substantial deficits were induced by diazepam, eszopiclone, and zolpidem at sleep-promoting doses [24].

Even if DORA levels sufficient to exceed the $\mathrm{OX}_{2} \mathrm{R}$ efficacy threshold are present at the onset of wake, emerging preclinical data indicate that these effects are expected to be benign relative to those induced by GABA-A receptor modulators. When evaluated acutely $(<4 \mathrm{~h}$ after treatment), DORAs have little or no impact on locomotor coordination in rats [35], or on memory or attention in rats and rhesus monkeys [24]. This is in 
stark contrast to BzRMs or non-BzRMs, which induce substantial deficits when measured acutely [24,35]. While these differential effects remain to be investigated clinically, results in preclinical species indicate another fundamental difference between blockade of orexin signaling and GABA-A receptor activation.

The sleep promoting effect of DORAs is the result of the inhibition of orexin-induced arousal primarily mediated through $\mathrm{OX}_{2} \mathrm{R}$. Genetically, loss of this receptor is associated with narcolepsy in dogs [36] and the hypersomnolent phenotype of mice lacking $\mathrm{OX}_{2} \mathrm{R}$ is similar to that of those lacking both receptors or Hcrt gene encoding orexin ligands $[37,38]$, while $\mathrm{OX}_{1} \mathrm{R}$ KOs reportedly display only a minor, sleep fragmentation phenotype [39]. Pharmacologically, $\mathrm{OX}_{2} \mathrm{R}$ selective antagonists induce sleep promoting effects similar to that of DORAs, while $\mathrm{OX}_{1} \mathrm{R}$ selective antagonists administered alone exhibit only minor, if detectable effects on vigilance state $[29,30]$. It has been suggested that $\mathrm{OX}_{1} \mathrm{R}$ inhibitory activity of DORAs may counter the effect of $\mathrm{OX}_{2} \mathrm{R}$ inhibition by these compounds through a dopamine-mediated mechanism [29], but further evaluation using alternative $\mathrm{OX}_{1} \mathrm{R}$ and $\mathrm{OX}_{2} \mathrm{R}$ selective antagonists of different selectivity has questioned this conclusion [30].

Based on these preclinical evaluations of structurally divergent DORAs, suvorexant exhibits a pharmacokinetic profile predicted to be advantageous for the treatment of insomnia. Analysis of the time course of suvorexant plasma concentrations determined in an early Phase 1 clinical trial indicates that concentrations sufficient for efficacy in humans $\left(0.33 \mu \mathrm{M}\right.$ for $65 \% \mathrm{OX}_{2} \mathrm{R}$ occupancy based on normalization from the rat transgenic model) are restricted to normal sleep periods while efficacy is maintained for a range of doses. Given their high $\mathrm{OX}_{2} \mathrm{R}$ occupancy threshold for efficacy, DORAs require a plasma concentration sufficient to maintain occupancy in order to promote sleep throughout the resting period in humans. For suvorexant, this is achieved with a plasma concentration $\mathrm{T}_{1 / 2}$ exceeding $8 \mathrm{~h}$. In early clinical trials, suvorexant exhibited an apparent terminal $\mathrm{T}_{1 / 2}$ of 9 to $13 \mathrm{~h}$ [40] - pharmacokinetic timing appropriate for sleep maintenance.

Although insomnia is a common disorder, its underlying mechanisms are still not fully understood. DORAs have been rationally designed specifically to promote sleep by blocking wakefulness and thus alleviate the symptoms of insomnia while minimizing potential offtarget activity that occurs with widespread signaling via GABA-A receptor modulators. By using antagonist compounds like suvorexant to block the arousal-promoting effects of orexin signaling in the brain, the oscillation in endogenous orexin pathway activation (highest signaling during active periods and diminished signaling during normal sleep times) is modified to mimic more closely the expected physiological state in normal sleep and wakefulness.

\section{Conclusion}

The combination of desirable pharmacokinetic and receptor-binding properties as well as a high level of $\mathrm{OX}_{2} \mathrm{R}$ occupancy necessary to antagonize the wake promoting effects of the endogenous orexin ligand allows DORAs to alleviate insomnia symptoms during normal sleep periods while avoiding residual somnolence during subsequent waking periods. These data support the thesis that DORAs such as suvorexant may have pharmacological and kinetic-binding properties appropriate for the treatment of insomnia.

\section{Methods}

All animal studies were performed in accordance with The National Research Council's Guide for the Care and Use of Laboratory Animals (http://www.nap.edu/catalog. php?record_id=12910) and were approved by the Merck Institutional Animal Care and Use Committee. All efforts were made to minimize animal use and suffering.

\section{Detection of orexin-A in cerebrospinal fluid}

CSF was collected via cisterna magna puncture similarly from male and female beagles and rhesus monkeys (Macaca mulatta) similarly. Propofol (i.v., 2-8 mg/kg, to effect ) anesthetized dogs were maintained on isofluorane anesthesia via an endotracheal tube. Using aseptic technique, a 1.5 inch spinal needle with stylet is introduced through the skin and subcutaneous tissue and then through the atlanto-occipital membrane which connects the first vertebrae with the skull and overlies the cisterna magna. The stylet is then removed from the needle and cerebrospinal fluid is allowed to flow into a collection tube. CSF was collected from conscious male and female rhesus monkeys (Macaca mulatta) using methods described previously [41], and similar to those procedures employed in dog.

CSF was collected from Male Sprague-Dawley rats (Taconic Farms, Hudson, NY) under isofluorane anesthesia (5\% with oxygen at $2 \mathrm{~L} / \mathrm{min}$ in an induction hood, $2 \%$ thereafter) and on a circulating water warming blanket. Heads were shaved from the posterior portion to the dorsal thoracic area exposing region just above the cisterna magna, and placed on stereotaxic apparatus to position the head of the rat at a $70-80^{\circ}$ bend. After identifying the area by palpation, a $25 \mathrm{~g} \times 5 / 8^{\prime}$ " butterfly needle, with 12 " of tubing (Terumo Surflo Winged Infusion Set, Terumo Corporation, Somerset, NJ) is slowly inserted into the cisterna magna of the rat. A small suction is applied from a syringe connected to the end of the winged infusion set until fluid is observed in the tubing. CSF is then collected by expulsion into a microfuge tube. CSF was similarly collected 
from male C57BL/6 mice (Taconic Farms, Hudson, NY) except that the procedure is a non-survival surgery in mice, and animals are rapidly euthanized following CSF recovery. For mice, a stereotaxic device is fashioned from the styrofoam $15 \mathrm{~mL}$ conical tube holder, and skin and muscle covering the head and neck area are removed to visualize the dura mater prior to CSF collection.

Concentrations of OX-A within CSF were quantified by immunoassay developed using the Meso Scale Discovery (MSD) electrochemiluminescence detection technology platform (Gaithersburg, MD, USA). Purified polyclonal immunoglobulin G (G-003-36, Phoenix Peptide, Burlingame, CA, USA), raised in rabbit against OX-A (amino acids 16-33) amide, was used as the capture antibody. Goat anti-human polyclonal antibody against orexin-A (N-18) (sc-26491, Santa Cruz Biotechnology Inc., Santa Cruz, CA, USA) was used as the primary detection antibody. Sulfo-Tag-labeled anti-goat antibody, raised in donkey, was used as the secondary detection antibody and was provided by MSD (R32AG-5). Assay wash buffer (R61TX-1) was also sourced from MSD. Blocking buffer was generated by dissolving membrane blocking agent (RPN-2125, GE Healthcare, Buckinghamshire, UK) in MSD wash buffer (1.5 g per $50 \mathrm{~mL}$ ). Antibody and orexin standard diluent was made by diluting blocking buffer three-fold in wash buffer. Standard OX-A (full length peptide) was sourced from Phoenix Peptide (003-30, Burlingame, CA, USA).

Plates were incubated overnight with $25 \mu \mathrm{L}$ of capture antibody $(3.33 \mu \mathrm{g} / \mathrm{mL})$ and washed three times using MSD wash buffer $(200 \mu \mathrm{L}$ per well). Plates were then incubated with blocking buffer $(150 \mu \mathrm{L}$ per well) on a Titer Plate Shaker (Barnstead International, Dubuque, IA, USA) for $1 \mathrm{~h}$ at room temperature. After aspirating blocking buffer, orexin standards (reconstituted in antibody diluent) or samples ( $25 \mu \mathrm{L})$ were added to each well. The plates were sealed and incubated, shaking for $2 \mathrm{~h}$ at room temperature. Following incubation with standards and samples, plates were washed an additional three times with $200 \mu \mathrm{L}$ per well of wash buffer. Next, $25 \mu \mathrm{L}$ of primary antibody dilution $(1 \mu \mathrm{g}$ per $\mathrm{mL})$ was added to each well and plates were sealed and incubated while shaking for $1 \mathrm{~h}$ at room temperature. Following an additional wash step, $25 \mu \mathrm{L}$ of secondary antibody dilution $(0.5 \mu \mathrm{g}$ per $\mathrm{mL})$ was added to each well, and plates were sealed and incubated, shaking, for $1 \mathrm{~h}$ at room temperature. As a final step, $150 \mu \mathrm{L}$ of read buffer was added to each well and plates were read on an MSD sector imager. All measurements were performed in triplicate.

\section{EEG}

The mean time spent in sleep stages was determined in radio-telemetry-implanted mice, rats, dogs, and rhesus monkeys as first described by Renger and colleagues [42] and subsequently by Winrow and colleagues [12,18] with minor modifications. For baseline studies, recordings were taken continuously from unperturbed mice, rats, dogs, and monkeys for $6,6,10$, or 5 days, respectively, and the mean time spent in all sleep stages in 30-min intervals were averaged and plotted onto a single 24-h period (Figure 1). Almorexant is a DORA [43] that was previously in clinical development for the treatment of insomnia $[10,44]$. The clinical development program for almorexant was terminated in early 2011. For rat studies in which DORA-22, DORA-12, or almorexant were administered, a balanced 3-day cross-over design was employed in which all animals were treated alternately with vehicle (20\% Vitamin E d-alpha tocopheryl polyethylene glycol 1000 succinate [TPGS], orally [per os, p.o.]) and compound for 3 consecutive days with a 5-day intervening washout period, animals being divided randomly into either vehicle- or compound-first groups. In all cases, mean time in active wake, quiet wake, SWS, and REM sleep was determined for each 30-min interval for 3 days of each condition and averaged onto a single 24-h period. Automated sleep-stage data collection and analysis were performed as described in detail previously [12]. Statistical differences in mean time spent in active wake, quiet wake, SWS, and REM sleep between vehicle- and compound-treated groups at 30min time points were determined by a linear mixedeffects model applied t-test.

EEG responses to diazepam $(10 \mathrm{mg} / \mathrm{kg}$, p.o. in $0.5 \%$ methylcellulose); eszopiclone $(10 \mathrm{mg} / \mathrm{kg}$, p.o. in $20 \%$ Vitamin E TPGS) and DORA $22(30 \mathrm{mg} / \mathrm{kg}$, p.o. in $20 \%$ Vitamin E TPGS) were evaluated in rhesus monkeys implanted with subcutaneous telemetric devices (D70EEE; Data Sciences International, Arden Hills MN) housed in a 12:12 light cycle with lights-off at 16:30 and lights-on at 04:30. Animals were fed on a caloriecontrolled diet of laboratory chow supplemented with fruit and vegetables. Water was available ad libitum with the exception of those monkeys trained to perform cognitive tasks, for which access was restricted for up to $4 \mathrm{~h}$ prior to and during cognitive testing. Treatment occurred at 14:40 (Zeitgeber time [ZT] 10:10) in a balanced 1-day cross-over design: 1 day of drug or vehicle followed by 6 days of baseline followed by 1 day of vehicle or drug. Cognition tasks were scheduled for next-day evaluation as described below. Sleep/wake architecture was scored according to vigilance state (active wake, quiet wake, delta sleep I, delta sleep II, and REM sleep) at 30-minute intervals and analyzed as previously described [24]. Spectral analysis of continuous EEG was quantified between vehicle and compound after binning continuous frequencies into canonical frequency bands (reported herein: Delta, 0.5 - $4 \mathrm{~Hz}$; 
Theta, 4.0 - $7 \mathrm{~Hz}$; Gamma, 35.0 - $100.0 \mathrm{~Hz}$ ). qEEG values are spectral power (uV2) log transformed before analysis and averaged over 30-minute intervals, expressed as means $+/$ - SEM, and compared with vehicle using a mixed-model ANOVA at each time point with random effects for subject and date within subject in the $\mathrm{R}$ statistical computing environment (cran.us.rproject.org; the R Foundation for Statistical Computing, Vienna, Austria) using a linear mixed effects model for significance testing. Significant conditional differences are indicated as tick marks at the top of the graphs (short, $\mathrm{P} \leq 0.05$; medium, $\mathrm{P} \leq 0.01$; long, $\mathrm{P} \leq 0.001$ ) with gray vertical bars through significantly different data points.

\section{$\mathrm{OX}_{2} \mathrm{R}$ occupancy}

Occupancy of human $\mathrm{OX}_{2} \mathrm{R}$ in transgenic rats expressing the receptor via the rat enolase promoter was performed ex vivo in radioligand-binding-displacement assays essentially as previously described [21] with minor modifications. To determine the relationship between $\mathrm{OX}_{2} \mathrm{R}$ occupancy for a given compound over a full range of plasma and CSF concentrations, $\mathrm{hOX}_{2} \mathrm{R}$-expressing rats were dosed i.v. with compound. Immediately following $30 \mathrm{~min}$ of i.v. administration, animals were anesthetized, sacrificed, and CSF, blood, and brain tissue were harvested and frozen for analysis. Frozen tissue was weighed and thawed coincident with homogenization. The homogenate was pelleted at $21,000 \times \mathrm{g}$ for $1 \mathrm{~min}$ and the pellet was resuspended. A binding assay was run with brain tissue and radio ligand at $\sim 10 \times \mathrm{K}_{\mathrm{d}}$ and filtered at $12 \mathrm{~min}$ (in the linear association phase). Nonspecific binding was determined by the addition of 1000-fold excess unlabeled ligand. Experimental (dosed)specific binding was compared with control (vehicledosed) binding ([specific total counts minus specific experimental counts]/specific total counts $\times 100=$ percent occupancy). Raw occupancy values determined in this manner over a range of plasma and CSF values were then used to construct a normalized curve where the theoretical maximum occupancy value was defined as $100 \%$ and occupancies relative to plasma or CSF values were fit to a one-sided binding (hyperbola) curve (GraphPad Prism, San Diego, CA, USA). Plasma values determined from PSG experiments in satellite animals were then used to determine corresponding occupancy values from best fit curves for a given compound at $\mathrm{C}_{\max }$. In separate experiments, plasma, CSF, and brain tissue was collected at time points following dosing to directly measure compound levels and corresponding $\mathrm{OX}_{2} \mathrm{R}$ occupancies at these times. Resulting occupancy relative to measured plasma levels of compound was fit to a normalized binding curve as described previously [21].
$\mathrm{OX}_{2} \mathrm{R}$ occupancy in dogs and humans was calculated based on the plasma/occupancy relation determined in rats and corrected for the free fraction of suvorexant in each species. In dogs, suvorexant plasma levels determined in satellite animals coincident with PSG studies reported by Winrow and colleagues [12] were used to calculate $\mathrm{OX}_{2} \mathrm{R}$ occupancy levels based on standard curves of $\mathrm{OX}_{2} \mathrm{R}$ occupancy in rats versus the free fraction of plasma suvorexant levels. Human free plasma levels of suvorexant sufficient for $80 \% \mathrm{OX}_{2} \mathrm{R}$ occupancy were calculated based on extensive rat data and normalized for free fraction (rat: 1.4\%; human: 1\%). The plasma level of suvorexant calculated to correspond to $80 \%$ $\mathrm{OX}_{2} \mathrm{R}$ occupancy in humans is $0.71 \mu \mathrm{M}$ (free + bound) [17]. Human plasma levels of suvorexant collected in Phase $1(10,20,50$, and $76 \mathrm{mg}$ doses $)$ and Phase $2 / 3$ (steady state, $40 \mathrm{mg}$ ) clinical trials were plotted against the suvorexant plasma value calculated to correspond to the exposure required for the $\mathrm{OX}_{2} \mathrm{R}$ occupancy determined from standard $\mathrm{OX}_{2} \mathrm{R}$ occupancy versus free fraction exposure curves of preclinical species.

\section{Monkey Delayed Match to Sample (DMS) task}

All cognition testing occurred in the animal's home cage equipped with a touchscreen. Each DMS trial was initiated with a single 'sample' image $(150 \times 200$ pixels: 1.8 inches $\times 2.3$ inches) in one of eight colors presented at the center of a touchscreen. Evaluation began when the monkey touched the sample image, at which point the screen became blank for a retention period. Following the retention period, four choice images $(150 \times 200$ pixels) were presented, one in each corner of the screen. One of the four choice images matched the color of the sample image, whereas the three remaining 'distractor' images were drawn from the pool of remaining colors. A reinforcer was provided when the monkey touched the choice image that matched the color of the sample image. Incorrect choices were not reinforced and resulted in a $5 \mathrm{~s}$ timeout. On completion of the trial, an inter-trial interval of $5 \mathrm{~s}$ was presented prior to the next trial, and failure to respond to the samples or choice images within $30 \mathrm{~s}$ resulted in the screen turning blank for a $5 \mathrm{~s}$ timeout prior to initiating another trial. Test sessions comprised 96 trials or lasted for up to $45 \mathrm{~min}$. Three discrete retention intervals were titrated for each subject's baseline performance in the absence of compound to yield performances of approximately $80-100 \%$, $55-65 \%$, and $35-45 \%$ of responses being correct at short, medium, and long retention intervals, and ranged from $0.25-0.5 \mathrm{~s}, 2.5-14 \mathrm{~s}$, and 9-39 s, respectively. Response latencies to sample and choice images were also recorded. Values reported reflect the proportion of correct responses collapsed over all retention intervals. 
Differences from vehicle were examined using repeated measures ANOVA.

\section{Monkey Serial Choice Reaction Time (SCRT) task}

Each SCRT trial was initiated with the appearance of 10 blue square 'target' images evenly distributed at 3 -inch intervals around the perimeter of a touchscreen presented together with a centrally located circular 'centering' image (1.4 inch diameter circle). The task began with the monkey touching the centering image, which then turned gray. The monkey was then required to touch the centering image continuously throughout a variable pre-cue interval of 0.25-7.5 s. On completion of the pre-cue interval, one of the blue target images was cued by turning red for one of four cue durations before turning back to blue. To obtain a reward, the monkey was required to touch the target image that had been 'cued' red within a 5 s limited hold period. Inaccurate choices were not reinforced and resulted in a $3 \mathrm{~s}$ timeout. On completion of the trial, an inter-trial interval of $2 \mathrm{~s}$ was initiated prior to the next trial. A failure to respond to the centering image within $60 \mathrm{~s}$ resulted in the screen becoming blank for a $2 \mathrm{~s}$ timeout prior to the start of the next trial. If the monkey initiated a trial but removed its hand from the touchscreen prior to the appearance of the cue, the trial was terminated and the screen was blanked during a $2 \mathrm{~s}$ inter-trial interval. Sessions were terminated after $20 \mathrm{~min}$. Cue location and duration were pseudo-randomly assigned. Cue duration and the target size were titrated for each subject on the basis of performance during previous baseline sessions to yield a performance of $60-80 \%$ correct responses for the trials of the shortest cue duration. The briefest cue duration varied from $0.04-0.1 \mathrm{~s}$ and the cues varied in size from 0.2-0.7 inches, although each cue had the same touch-sensitive area of 1.75 inches. Values reported in the current study reflect the proportion of correct responses to targets after cues of the shortest duration only.

\section{Authors' contributions}

ALG, CJW, JJR wrote and edited major portions of the manuscript with significant interpretive and editorial comments by all authors, particularly SDK, PJC, TMCD, and PLT Rodent, dog and rhesus orexin level determinations were performed by JB with analytical and technical contributed by LY SLG, $J B, J S, A S$ and SVF performed rodent polysomnography studies with study design, additional data analysis and interpretation contributed by ALG, PLT, and JJR Monkey polysomnography studies were performed by $J B, A S$, and SJT with study design, additional data analysis and interpretation contributed by ALG, PLT, and JJR Monkey cognition study design, analysis and interpretation by SJT, JU and AS Pharmacokinetic analysis and interpretation by DC, KLY, SDK and ALG Occupancy study execution and analysis by MS, CMH with study design, additional analysis and interpretation by ALG, DC, KLY All authors' read and approved the final manuscript.

\section{Acknowledgements}

All authors are employed by Merck Research Laboratories, receive salary and research support from Merck and Co., Inc., and potentially own stock in the company. Editorial support was provided by Gary Dever, Ph.D. at Complete Medical Communications and was funded by Merck \& Co., Inc.

\section{Author details}

'Department of Neuroscience, Merck Research Laboratories, West Point, PA, USA. ${ }^{2}$ Department of In Vivo Pharmacology, Merck Research Laboratories, West Point, PA, USA. ${ }^{3}$ Department of Pharmacokinetics and Drug Metabolism, Merck Research Laboratories, West Point, PA, USA. ${ }^{4}$ Department of Medicinal Chemistry, Merck Research Laboratories, West Point, PA, USA.

Received: 24 April 2013 Accepted: 21 August 2013

Published: 28 August 2013

\section{References}

1. Espana RA, Scammell TE: Sleep neurobiology from a clinical perspective. Sleep 2011, 34:845-858.

2. Gotter AL, Webber AL, Coleman PJ, Renger JJ, Winrow CJ: International Union of Basic and Clinical Pharmacology. LXXXVI. Orexin receptor function, nomenclature and pharmacology. Pharmacol Rev 2012, 64:389-420.

3. Taheri S, Sunter D, Dakin C, Moyes S, Seal L, Gardiner J, Rossi M, Ghatei M, Bloom S: Diurnal variation in orexin A immunoreactivity and preproorexin mRNA in the rat central nervous system. Neurosci Lett 2000, 279:109-112.

4. Zeitzer JM, Buckmaster CL, Parker KJ, Hauck CM, Lyons DM, Mignot E: Circadian and homeostatic regulation of hypocretin in a primate model: Implications for the consolidation of wakefulness. J Neurosci 2003, 23:3555-3560

5. De Lecea L, Kilduff TS, Peyron C, Gao XB, Foye PE, Danielson PE, Fukuhara C, Battenberg ELF, Gautvik VT, Bartlett FS, Frankel WN, van den Pol AN, Bloom FE, Gautvik KM, Sutcliffe JG: The hypocretins: Hypothalamus-specific peptides with neuroexcitatory activity. Proc Natl Acad Sci U S A 1998 95:322-327.

6. Sakurai T, Amemiya A, Ishii M, Matsuzaki I, Chemelli RM, Tanaka H, Williams SC, Richardson JA, Kozlowski GP, Wilson S, Arch JRS, Buckingham RE, Haynes AC, Carr SA, Annan RS, McNulty DE, Liu WS, Terrett JA, Elshourbagy NA, Bergsma DJ, Yanagisawa M: Orexins and orexin receptors: A family of hypothalamic neuropeptides and $\mathrm{G}$ protein-coupled receptors that regulate feeding behavior. Cell 1998, 92:573-585.

7. Hagan JJ, Leslie RA, Patel S, Evans ML, Wattam TA, Holmes S, Benham CD, Taylor SG, Routledge C, Hemmati P, Munton RP, Ashmeade TE, Shah AS, Hatcher JP, Hatcher PD, Jones DNC, Smith MI, Piper DC, Hunter AJ, Porter RA, Upton N: Orexin A activates locus coeruleus cell firing and increases arousal in the rat. Proc Natl Acad Sci U S A 1999, 96:10911-10916.

8. Mieda M, Willie JT, Hara J, Sinton CM, Sakurai T, Yanagisawa M: Orexin peptides prevent cataplexy and improve wakefulness in an orexin neuron-ablated model of narcolepsy in mice. Proc Natl Acad Sci U S A 2004, 101:4649-4654.

9. Piper DC, Upton N, Smith MI, Hunter AJ: The novel brain neuropeptide, orexin-A, modulates the sleep-wake cycle of rats. Eur J Neurosci 2000, 12:726-730.

10. Brisbare-Roch C, Dingemanse J, Koberstein R, Hoever P, Aissaoui H, Flores S, Mueller C, Nayler O, Van Gerven J, De Haas SL, Hess P, Qiu CB, Buchmann S, Scherz M, Weller T, Fischli W, Clozel M, Jenck F: Promotion of sleep by targeting the orexin system in rats, dogs and humans. Nat Med 2007, 13:150-155.

11. Li AH, Nattie E: Antagonism of rat orexin receptors by almorexant attenuates central chemoreception in wakefulness in the active period of the diurnal cycle. J Physiol 2010, 588:2935-2944.

12. Winrow CJ, Gotter AL, Cox CD, Doran SM, Tannenbaum PL, Breslin MJ, Garson SL, Fox SV, Harrell CM, Stevens J, Reiss DR, Cui D, Coleman PJ, Renger JJ: Promotion of sleep by suvorexant - a novel dual orexin receptor antagonist. J Neurogenet 2011, 25:52-61.

13. Roehrs T, Roth T: Insomnia pharmacotherapy. Neurotherapeutics 2012, 9:728-738.

14. Roth T: A physiologic basis for the evolution of pharmacotherapy for insomnia. J Clin Psychiatry 2007, 68(Suppl 5):13-18.

15. Bettica P, Squassante L, Groeger JA, Gennery B, Winsky-Sommerer R, Dijk DJ: Differential effects of a dual orexin receptor antagonist (SB-649868) and zolpidem on sleep initiation and consolidation, SWS, REM sleep, and EEG power spectra in a model of situational insomnia. Neuropsychopharmacology 2012, 37:1224-1233

16. Di Fabio R, Pellacani A, Faedo S, Roth A, Piccoli L, Gerrard P, Porter RA, Johnson CN, Thewlis K, Donati D, Stasi L, Spada S, Stemp G, Nash D, Branch 
C, Kindon L, Massagrande M, Poffe A, Braggio S, Chiarparin E, Marchioro C,

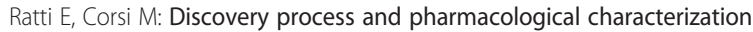
of a novel dual orexin 1 and orexin 2 receptor antagonist useful for treatment of sleep disorders. Bioorg Med Chem Lett 2011, 21:5562-5567.

17. Herring WJ, Snyder E, Budd K, Hutzelmann J, Snavely D, Liu K, Lines C, Roth $T$, Michelson D: Orexin receptor antagonism for treatment of insomnia: A randomized clinical trial of suvorexant. Neurology 2012, 79:2265-2274.

18. Winrow CJ, Gotter AL, Cox CD, Tannenbaum PL, Garson SL, Doran SM, Breslin MJ, Schreier JD, Fox SV, Harrell CM, Stevens J, Reiss DR, Cui D, Coleman PJ, Renger JJ: Pharmacological characterization of MK-6096 - a dual orexin receptor antagonist for insomnia. Neuropharmacology 2012, 62:978-987

19. Coleman PJ, Schreier JD, Cox CD, Breslin MJ, Whitman DB, Bogusky MJ, McGaughey GB, Bednar RA, Lemaire W, Doran SM, Fox SV, Garson SL, Gotter AL, Harrell CM, Reiss DR, Cabalu TD, Cui D, Prueksaritanont T, Stevens J, Tannenbaum PL, Ball RG, Stellabott J, Young SD, Hartman GD, Winrow CJ, Renger JJ: Discovery of [(2R,5R)-5-\{((5-fluoropyridin-2-yl)oxy]methyl\}2-methylpiperidin-1-yl][5-methyl-2 -(pyrimidin-2-yl)phenyl]methanone (MK-6096): a dual orexin receptor antagonist with potent sleeppromoting properties. ChemMedChem 2012, 7:415-24. 337.

20. Fox SV, Gotter AL, Tye SJ, Garson SL, Savitz AT, Uslaner JM, Brunner JI, Tannenbaum PL, McDonald TP, Hodgson R, Yao L, Bowlby MR, Kuduk SD, Coleman PJ, Hargreaves R, Winrow CJ, Renger JJ: Quantitative electroencephalography within sleep/wake states differentiates GABAA modulators eszopiclone and zolpidem from dual orexin receptor antagonists in rats. Neuropsychopharmacology 2013. doi:10.1038/ npp.2013.139

21. Cox CD, Breslin MJ, Whitman DB, Schreier JD, McGaughey GB, Bogusky MJ, Roecker AJ, Mercer SP, Bednar RA, Lemaire W, Bruno JG, Reiss DR, Harrell CM, Murphy KL, Garson SL, Doran SM, Prueksaritanont T, Anderson WB, Tang C, Roller S, Cabalu TD, Cui D, Hartman GD, Young SD, Koblan KS, Winrow CJ, Renger JJ, Coleman PJ: Discovery of the dual orexin receptor antagonist [(7R)-4-(5-chloro-1,3-benzoxazol-2-yl)-7-methyl-1,4-diazepan1-yl][5-methy I-2-(2H-1,2,3-triazol-2-yl)phenyl]methanone (MK-4305) for the treatment of insomnia. J Med Chem 2010, 53:5320-5332.

22. Gotter AL, Roecker AJ, Hargreaves R, Coleman PJ, Winrow CJ, Renger JJ: Orexin receptors as therapeutic drug targets. Prog Brain Res 2012, 198:163-88.

23. Faedo S, Perdona E, Antolini M, Di FR, Merlo PE, Corsi M: Functional and binding kinetic studies make a distinction between OX1 and OX2 orexin receptor antagonists. Eur J Pharmacol 2012, 692:1-9.

24. Uslaner JM, Tye SJ, Eddins DM, Wang X, Fox SV, Savitz AT, Binns J, Cannon CE, Garson SL, Yao L, Hodgson R, Stevens J, Bowlby MR, Tannenbaum PL, Brunner J, McDonald TP, Gotter AL, Kuduk SD, Coleman PJ, Winrow CJ, Renger JJ: Orexin receptor antagonists differ from standard sleep drugs by promoting sleep at doses that do not disrupt cognition. Sci Transl Med 2013, 5:179ra44.

25. Abadie P, Rioux P, Scatton B, Zarifian E, Barre L, Patat A, Baron JC: Central benzodiazepine receptor occupancy by zolpidem in the human brain as assessed by positron emission tomography. Eur J Pharmacol 1996, 295:35-44.

26. Martins PJ, D'Almeida V, Pedrazzoli M, Lin L, Mignot E, Tufik S: Increased hypocretin-1 (orexin-a) levels in cerebrospinal fluid of rats after shortterm forced activity. Regul Pept 2004, 117:155-8.

27. Allen RP, Mignot E, Ripley B, Nishino S, Earley CJ: Increased CSF hypocretin1 (orexin-A) in restless legs syndrome. Neurology 2002, 59:639-41.

28. Nishino S, Ripley B, Overeem S, Lammers GJ, Mignot E: Hypocretin (orexin) deficiency in human narcolepsy. Lancet 2000, 355:39-40.

29. Dugovic C, Shelton JE, Aluisio LE, Fraser IC, Jiang XH, Sutton SW, Bonaventure P, Yun SJ, Li XR, Lord B, Dvorak CA, Carruthers NI, Lovenberg TW: Blockade of Orexin-1 Receptors Attenuates Orexin-2 Receptor Antagonism-Induced Sleep Promotion in the Rat. J Pharmacol Exp Ther 2009, 330:142-151.

30. Morairty SR, Revel FG, Malherbe P, Moreau JL, Valladao D, Wettstein JG, Kilduff TS, Borroni E: Dual hypocretin receptor antagonism is more effective for sleep promotion than antagonism of either receptor alone. PLoS One 2012, 7:e39131.

31. Farde L, Nordström AL, Wiesel FA, Pauli S, Halldin C, Sedvall G: Positron emission tomographic analysis of central D1 and D2 dopamine receptor occupancy in patients treated with classical neuroleptics and clozapine. Relation to extrapyramidal side effects. Arch Gen Psychiatry 1992, 49:538-44.
32. Wong DF, Tauscher J, Gründer G: The role of imaging in proof of concept for CNS drug discovery and development. Neuropsychopharmacology 2009, 34:187-203.

33. Dijk DJ, James LM, Peters $S$, Walsh JK, Deacon S: Sex differences and the effect of gaboxadol and zolpidem on EEG power spectra in NREM and REM sleep. J Psychopharmacol 2010, 24:1613-1618.

34. Walsh JK, Deacon S, Dijk DJ, Lundahl J: The selective extrasynaptic GABAA agonist, gaboxadol, improves traditional hypnotic efficacy measures and enhances slow wave activity in a model of transient insomnia. Sleep 2007, 30:593-602.

35. Steiner MA, Lecourt H, Strasser DS, Brisbare-Roch C, Jenck F: Differential effects of the dual orexin receptor antagonist almorexant and the GABA (A)-alpha1 receptor modulator zolpidem, alone or combined with ethanol, on motor performance in the rat. Neuropsychopharmacology 2011, 36:848-856.

36. Lin L, Faraco J, Li R, Kadotani H, Rogers W, Lin XY, Qiu XH, De Jong PJ, Nishino S, Mignot E: The sleep disorder canine narcolepsy is caused by a mutation in the hypocretin (orexin) receptor 2 gene. Cell 1999, 98:365-376.

37. Chemelli RM, Willie JT, Sinton CM, Elmquist JK, Scammell T, Lee C, Richardson JA, Williams SC, Xiong YM, Kisanuki Y, Fitch TE, Nakazato M, Hammer RE, Saper CB, Yanagisawa M: Narcolepsy in orexin knockout mice: Molecular genetics of sleep regulation. Cell 1999, 98:437-451.

38. Willie JT, Chemelli RM, Sinston CM, Tokita H, Williams SC, Kisanuki YY, Marcus JN, Lee C, Elmquist JK, Kohlmeier KA, Leonard CS, Richardson JA, Hammer RE, Yanagisawa M: Distinct narcolepsy syndromes in Orexin receptor-2 and Orexin null mice: Molecular genetic dissection of nonREM and REM sleep regulatory processes. Neuron 2003, 38:715-730.

39. Willie JT, Chemelli RM, Sinton CM, Yanagisawa M: To eat or to sleep? Orexin in the regulation of feeding and wakefulness. Annu Rev Neurosci 2001, 24:429-458

40. Sun H, Kennedy D, Lewis N, Laethem T, Yee K, Li X, Hoon J, Van Bortel L, Rosen L, Chodakewitz J, Wagner JA, Murphy MG: The single dose pharmacokinetic (PK) and pharmacodynamic (PD) profiles of suvorexant (MK-4305); a dual orexin receptor antagonist, in healthy male subjects. Clin Pharmacol Ther 2012, 91(Suppl 1):S29.

41. Gilberto DB, Zeoli AH, Szczerba PJ, Gehret JR, Holahan MA, Sitko GR, Johnson CA, Cook JJ, Motzel SL: An alternative method of chronic cerebrospinal fluid collection via the cisterna magna in conscious rhesus monkeys. Contemp Top Lab Anim Sci 2003, 42:53-59.

42. Renger JJ, Dunn SL, Motzel SL, Johnson C, Koblan KS: Sub-chronic administration of zolpidem affects modifications to rat sleep architecture. Brain Res 2004, 1010:45-54.

43. Malherbe P, Borroni E, Pinard E, Wettstein JG, Knoflach F: Biochemical and electrophysiological characterization of almorexant, a dual orexin 1 receptor (OX1)/orexin 2 receptor (OX2) antagonist: comparison with selective OX1 and OX2 antagonists. Mol Pharmacol 2009, 76:618-631.

44. Dingemanse J, Dorffner G, Hajak G, Benes H, Danker-Hopfe H, Polo O, Saletu B, Barbanoj MJ, Pillar G, Penzel T, Chiossi E, Hoever P: Proof-of-concept study in primary insomnia patients with ACT-078573, a dual orexin receptor antagonist [abstract]. Sleep Biol Rhythms [5th World Congr World Fed Sleep Res Sleep Med Soc] 2007, 5(Suppl). A194.

doi:10.1186/1471-2202-14-90

Cite this article as: Gotter et al:: The duration of sleep promoting efficacy by dual orexin receptor antagonists is dependent upon receptor occupancy threshold. BMC Neuroscience 2013 14:90. 